Published in final edited form as:

Am J Infect Control. 2013 April ; 41(4): 286-300. doi:10.1016/j.ajic.2013.01.002.

\title{
National Healthcare Safety Network (NHSN) Report, Data Summary for 2011, Device-associated Module
}

\author{
Margaret A. Dudeck, MPH, CPH, Teresa C. Horan, MPH, Kelly D. Peterson, BBA, Katherine \\ Allen-Bridson, RN, BSN, MScPH, CIC, Gloria Morrell, RN, MS, MSN, CIC, Angela Anttila, \\ RN, MSN, NPC, CIC, Daniel A. Pollock, MD, and Jonathan R. Edwards, MStat \\ Division of Healthcare Quality Promotion, National Center for Emerging, Zoonotic, and Infectious \\ Diseases, Centers for Disease Control and Prevention, Public Health Service, U.S. Department of \\ Health and Human Services, Atlanta, Georgia
}

\section{Background}

This report is a summary of Device-associated (DA) Module data collected by hospitals participating in the National Healthcare Safety Network (NHSN) for events occurring from January through December 2011 and reported to the Centers for Disease Control and Prevention (CDC) by August 1, 2012. This report updates previously published DA Module data from NHSN and provides contemporary comparative rates. ${ }^{1}$ This report complements other NHSN reports, including national and state-specific reports of standardized infection ratios (SIRs) for select healthcare-associated infections (HAIs). ${ }^{2,3,4}$

NHSN data collection, reporting, and analysis are organized into three components: Patient Safety, Healthcare Personnel Safety, and Biovigilance, and use standardized methods and definitions in accordance with specific module protocols. ${ }^{5,6,7}$ Institutions may use modules singly or simultaneously, but once selected, they must be used for a minimum of one calendar month for the data to be included in CDC analyses. All infections are categorized using standard CDC definitions that include laboratory and clinical criteria. ${ }^{7}$ The DA Module may be used by facilities other than hospitals, including outpatient dialysis centers. A report of data from this module for outpatient dialysis centers was published separately. ${ }^{8}$ NHSN facilities contributing HAI surveillance data to this report did so voluntarily, in response to state mandatory reporting requirements or in compliance with the Centers for Medicare and Medicaid Services' (CMS) Hospital Inpatient Quality Reporting (IQR) Program. CDC aggregated these data into a single national database for 2011, consistent with the stated purposes of NHSN, which were to:

- Collect data from a sample of healthcare facilities in the United States to permit valid estimation of the magnitude of adverse events among patients and healthcare personnel.

- Collect data from a sample of healthcare facilities in the United States to permit valid estimation of the adherence to practices known to be associated with prevention of these adverse events.

- Analyze and report collected data to permit recognition of trends. 
- Provide facilities with risk-adjusted metrics that can be used for inter-facility comparisons and local quality improvement activities.

- Assist facilities in developing surveillance and analysis methods that permit timely recognition of patient and healthcare worker safety problems and prompt intervention with appropriate measures.

- Conduct collaborative research studies with NHSN member facilities (e.g., describe the epidemiology of emerging healthcare-associated infection [HAI] and pathogens, assess the importance of potential risk factors, further characterize HAI pathogens and their mechanisms of resistance, and evaluate alternative surveillance and prevention strategies).

- Comply with legal requirements - including but not limited to state or federal laws, regulations, or other requirements - for mandatory reporting of healthcare facilityspecific adverse event, prevention practice adherence, and other public health data.

- Enable healthcare facilities to report HAI and prevention practice adherence data via NHSN to the U.S. Centers for Medicare and Medicaid Services (CMS) in fulfillment of CMS's quality measurement reporting requirements for those data.

- Provide state departments of health with information that identifies the healthcare facilities in their state that participate in NHSN.

- Provide to state agencies, at their request, facility-specific, NHSN patient safety component and healthcare personnel safety component adverse event and prevention practice adherence data for surveillance, prevention, or mandatory public reporting.

Patient- and facility-specific data reported to CDC are kept confidential in accordance with sections 304, 306, and 308(d) of the Public Health Service Act (42 USC 242b, 242k, and $242 \mathrm{~m}(\mathrm{~d}))$.

\section{Methods}

\section{Data Collection Methods}

For reporting to the DA Module, healthcare facility personnel responsible for infection prevention and patient safety may choose, with consideration of state mandates, federal reporting programs, and prevention initiatives, to collect data on central line-associated primary bloodstream infections (CLABSI), ventilator-associated pneumonias (VAP), or urinary catheter-associated urinary tract infections (CAUTI) that occur in patients staying in a patient care location such as a critical or intensive care unit (ICU), specialty care area, or inpatient ward. In NHSN, locations are further stratified according to patient population: adults, children, or neonates (in tables, pediatric and neonatal locations are so noted). In neonatal intensive care unit (NICU) locations (level III or level II/III), infection preventionists (IPs) collect data on central line-associated and umbilical catheter-associated BSI or VAP that occur in patients in each of five birth-weight categories ( $\leq 750 \mathrm{~g}, 751-1000$ g, $1001-1500 \mathrm{~g}, 1501-2500 \mathrm{~g}$, and $>2500 \mathrm{~g}$ ); data on CAUTI are not collected as part of the NHSN protocols in any NICU location. Corresponding location-specific denominator 
data consisting of patient-days and specific device-days are also collected by IPs or other trained personnel.

In non-NICU locations, the device-days consist of the total number of central line-days, urinary catheter-days, or ventilator-days. For specialty care areas, such as hematology/ oncology and hematopoietic stem cell transplant locations, central line days are split into those with only a permanent central line vs. those with temporary central lines (with or without a permanent central line). In NICU locations, the device-days consist of the total number of central line-days and umbilical catheter-days, or ventilator days for each birthweight category.

\section{Data Analysis Methods}

Compared to the previous report, five new locations - pediatric surgical critical care, long term care rehabilitation unit, long term acute care critical care, long term acute care ward, and inpatient rehabilitation facility- had sufficient data to be included in this report. ${ }^{11}$

Locations were further stratified by unit bed size and/or major teaching status to determine if pooled mean rates, medians, and empirical distributions significantly differed between two groups for all DA infections; if differences were present, the strata were retained for reporting. Comparisons of pooled mean rates were performed using Poisson regression. These comparisons could be influenced by potential outlier rates from locations with disproportionately large denominators. Therefore, greater weight was given to the results of nonparametric tests comparing the medians for location shift and empirical distributions for assessing differences across the range of reported rates. These nonparametric comparisons by definition require no validity assumptions and provide test results that are not subject to the potential weighting influence of high or low rates with large denominators. Comparisons of the median and percentile distribution were made if there were at least 50 locations contributing to one or more strata and at least 20 locations contributing to the percentile distribution in both strata.

Existing strata were retained for adult combined medical/surgical ICUs, medical ICUs, and surgical ICUs. The data for adult combined medical/surgical ICUs were split by hospital type and unit bedsize, resulting in three groups: "major teaching," "all others" with unit bedsize $₫ 5$ beds, and "all others" with unit bedsize $>15$. The data for adult medical ICUs and adult surgical ICUs were split into two groups by teaching status. Facilities selfidentified teaching status through an annual facility survey. Major teaching status was defined as a hospital that is an important part of the medical school teaching program in which the majority of medical students rotate through multiple clinical services. Adult bone marrow transplant and adult hematology/oncology locations were also evaluated to assess importance of status as an oncology hospital, but differences were not significant and no new strata were retained.

Device utilization (DU) was calculated as a ratio of device days to patient days for each location type. As such, the DU of a location is one measure of the use of invasive devices and constitutes an extrinsic risk factor for healthcare-associated infection. ${ }^{9}$ DU may also serve as a marker for severity of illness of patients (i.e. more severely ill patients are more 
likely to require an invasive device) which is another reflection of the intrinsic susceptibility to infection.

Data from at least 5 different reporting units of a given location type were used to determine pooled mean DA infection rates and DU ratios. Percentile distributions were determined if there were data from at least 20 different locations, excluding rates or DU ratios for locations that did not report at least 50 device-days or patient-days. Because of these requirements, the number of locations contributing data may vary among the tables.

\section{Results}

In 2011, 3,854 hospitals reported at least one month of DA denominator data for some patient cohorts under surveillance. These 3,854 hospitals were located in 53 states, territories, and the District of Columbia and were predominantly general acute care hospitals (Table 1); approximately two-thirds were smaller hospitals of 200 beds or less (65\%), and only $10.9 \%$ were categorized as major teaching facilities (Table 2). Additionally, $60 \%$ of the hospitals included in this report are located in states with a mandate for reporting at least one type of DA infection to NHSN. Where data volume was sufficient for this report, we tabulated DA infection rates and DU ratios for January through December 2011 (Tables 310). Data on the specific criteria used to report DA infections are provided in Tables 11-18.

Tables 3-6 update and augment previously published DA rates and DU ratios by type of non-NICU locations. ${ }^{11}$ Beginning in 2012, long term acute care (LTAC) units were recategorized by acuity level into critical care or ward designations; therefore, in order to align with current data reporting methods in this location type, LTAC data in this report have been categorized in the same manner. Additionally, data from inpatient rehabilitation facilities (IRFs), as defined by the Centers for Medicare and Medicaid Services (CMS), have been reported separately from non-IRF rehabilitation wards within acute care hospitals.

Tables 7-10 update and augment the previously published, DA rates and DU ratios by birthweight category for NICU locations. ${ }^{1}$ Beginning in January 2012, CLABSI data in NICU locations are no longer collected according to central line type (i.e., central line and umbilical catheter); in order to align with the current reporting of these data, CLABSI rates and DU ratios for NICUs are not stratified by line type in this report.

Tables 11-18 provide data on select attributes of the DA infections for each location. For example, Tables 11, 12, 15 and 16 show the frequency and percent distribution of the specific sites of CLABSI and the criteria used for identifying these infections. Note that for these tables, criteria 2 and 3 have been combined.

\section{Discussion}

This report summarizes the HAI data reported to the DA module of NHSN during 2011. The data in this report continue to be restricted to a single year for several reasons. First, NHSN saw continued growth in participation due to state mandates and federal reporting programs and because of this, there were sufficient data reported in 2011 to support the analysis of a single year of data (e.g., considerable data contributing to the pooled means, most location 
types with >20 locations reporting), thus obviating the need to combine data with previous years. Second, analyzing one year of data removes the need to assess the influence of any large increase of new reporters in a single year of a multiyear summary measure. Finally, by restricting data to a single year, changes in HAI rates are more apparent and can highlight continued prevention efforts in different patient care areas. This strategy also fulfills the need for more timely publication of comparative rates.

The characteristics of hospitals reporting to NHSN are similar to those seen in the last published report, although this report demonstrates a slight increase in contribution from smaller hospitals. ${ }^{1}$ Based on the number of facilities reporting, overall contribution to the device-associated module increased by $56 \%$ from the last report. ${ }^{11}$ This increase in reporting is largely attributed to hospitals' participation in the CMS Hospital Inpatient Quality Reporting Program which requires participants to use NHSN as the tool to report CLABSI data from all adult, pediatric, and neonatal ICUs beginning in January 2011. While much of this growth impacted the volume of CLABSI reporting in ICUs, there is an indication of increased participation in non-ICU locations for CLABSI reporting, as well as reporting for other HAIs in this module.

Extensive analyses of the impact of hospital type on all DA infection rates were performed for select ICU locations. Hospital type continues to be a significant factor for all three DA infection rates and percentile distributions in medical ICUs and surgical ICUs. Additionally, hospital type and bed size both continue to be significant factors in DA infection rates for medical/surgical ICUs. Note that while the CLABSI rates between unit bedsize strata in medical/surgical "all other" ICUs are equal (Table 3), the percentile distributions were shown to be significantly different as a result of nonparametric statistical tests. Therefore, this stratification by unit bedsize in "all other" medical/surgical ICUs was retained. Adult bone marrow transplant and adult hematology/oncology locations were not further stratified by hospital type (i.e., oncology hospital vs. all other acute care hospitals) as the results of the statistical tests indicated that the differences in the strata were not statistically significant. Beginning in 2013, oncology hospitals will be provided with fourteen oncology-specific CDC locations with which to identify for device-associated infection surveillance. As the volume of these data become sufficient, future analyses will continue to assess any potential differences in this specialized population.

Tables 11-18 were included to aid the reader in interpreting the DA infection rates data. One important use of these data is to better understthe distribution of DA infections by type of reporting criterion nationally. For example, approximately $82 \%$ of the CLABSIs from adult and pediatric ICU and inpatient wards were identified using the least subjective criterion (1) which attributes the CLABSI to a recognized pathogen; however, for NICUs, approximately two-thirds used this criterion, resulting in a greater percentage of CLABSIs in this population that were identified with common commensals. Similarly, the specific type of ventilator-associated pneumonia (VAP) most frequently reported, regardless of location, was the clinical criterion (PNU1) which relies on the somewhat subjective interpretations of clinical findings. 
As more and diverse types of facilities participate in NHSN either voluntarily or by mandate, the need for careful scrutiny of the data increases. We will continue to assess how the changing composition of facilities and the changing proportion of data contributed by various types of facilities impact the rates and their distributions so that the best possible risk-adjusted comparative data may be provided in future reports.

To improve the reliability of data reported to NHSN, several protocol changes are set to occur in January 2013. The majority of these changes are with respect to timing and implementation of two-day rules to clarify infections that are healthcare-associated, association of device use to HAI, and attribution of HAI to an inpatient location after transfer or to a hospital after discharge. In addition, NHSN will add criteria for mucosal barrier injury laboratory-confirmed bloodstream infections. Finally, the VAP definition will no longer apply to adult patients (i.e., $\geq 18$ years of age) and this definition will be replaced by ventilator-associated events (VAEs). ${ }^{10} \mathrm{We}$ will carefully assess the potential impact of these changes on HAI incidence as these data are reported.

For those who do not report to NHSN but would like to use these data for comparison, the information must first be collected from your hospital in accordance with the methods described for NHSN. ${ }^{5,6,7}$ Refer to Appendices A and B for further instructions. Appendix A discusses the calculation of infection rates and DU ratios for the DA Module. Appendix B gives a step-by-step method for interpretation of percentiles of infection rates or DU ratios. Although a high rate or ratio (>90th percentile) does not necessarily define a problem, it does suggest an area for further investigation. Similarly, a low rate or ratio $(<10$ th percentile) may be the result of inadequate infection detection.

Facilities should use the data in this report and their own data to guide local prevention strategies and other quality improvement efforts to reduce the occurrence of infections as much as possible. The data presented in this report can be used to prioritize prevention efforts in those patient care areas that are shown to have the highest incidence of DA infections and/or high device utilization. Facilities may also wish to set targets based on the percentile distributions provided in this report in an effort to strive for lower rates and greater prevention success. The authors are indebted to the NHSN participants for their ongoing efforts to monitor infections and improve patient safety. We also gratefully acknowledge our colleagues in the Division of Healthcare Quality Promotion who tirelessly support this unique public health network.

\section{Acknowledgments}

The findings and conclusions of the report are those of the authors and do not necessarily represent the official position of the Centers for Disease Control and Prevention.

\section{References}

1. Dudeck MA, Horan TC, Peterson KD, Allen-Bridson K, Morrell GC, Pollock DA, Edwards JR. National Healthcare Safety Network (NHSN) report, data summary for 2010, device-associated module. Am J Infect Control. 2011; 39:798-816. [PubMed: 22133532] 
2. Centers for Disease Control and Prevention. State-specific HAI standardized infection ratio (SIR) report. Jan-Jun. 2009 Available from: http://www.cdc.gov/HAI/pdfs/stateplans/ SIR_05_25_2010.pdf. Accessed October 25, 2012

3. Centers for Disease Control and Prevention. National HAI standardized infection ratio (SIR) report. Jul-Dec. 2009 Available from: http://www.cdc.gov/HAI/pdfs/stateplans/SIR-2010_JunDec2009.pdf. Accessed October 25, 2012

4. Centers for Disease Control and Prevention. State-specific supplement to the national healthcareassociated infection standardized infection ratio (SIR) report: July 2009 through December 2009. Available from: http://www.cdc.gov/HAI/pdfs/stateplans/state-specific-hai-sir-july-dec2009r.pdf. Accessed October 25, 2012

5. Centers for Disease Control and Prevention. Outline for healthcare-associated infection surveillance. Available from: http://www.cdc.gov/nhsn/PDFS/OutlineForHAISurveillance.pdf. Accessed October 25,2012

6. Centers for Disease Control and Prevention. NHSN manual: patient safety component protocols. Available from: http://www.cdc.gov/nhsn/TOC_PSCManual.html. Accessed October 25, 2012

7. Centers for Disease Control and Prevention. Surveillance definition of healthcare-associated infection and criteria for specific types of infections in the acute care setting. Available from: http:// www.cdc.gov/nhsn/PDFs/pscManual/17pscNosInfDef_current.pdf. Accessed October 25, 2012

8. Klevens RM, Edwards JR, Andrus ML, Peterson KD, Dudeck MA, Horan TC. the NHSN participants in Outpatient Dialysis Surveillance. Dialysis Surveillance Report: National Healthcare Safety Network (NHSN)-Data Summary for 2006. Seminars in Dialysis. 2008; 21(1):24-28. [PubMed: 18251954]

9. Jarvis WR, Edwards JR, Culver DH, Hughes JM, Horan T, Emori TG, et al. Nosocomial infection rates in adult and pediatric intensive care units in the United States. Am J Med. 1991; 91(Suppl 3B): 185S-91S. [PubMed: 1928163]

10. Centers for Disease Control and Prevention. Ventilator-associated events. Available from: http:// www.cdc.gov/nhsn/psc_da-vae.html. Accessed October 20, 2012 


\section{Table 1}

NHSN hospitals contributing data used in this report

\begin{tabular}{|c|c|}
\hline Hospital type & $\mathbf{N}(\%)$ \\
\hline Children's & $62(1.6)$ \\
\hline General, including acute, trauma, and teaching & $3,426(88.9)$ \\
\hline Long Term Acute Care & $192(5.0)$ \\
\hline Military & $25(0.6)$ \\
\hline Oncology & $10(0.3)$ \\
\hline Orthopedic & $13(0.3)$ \\
\hline Psychiatric & $10(0.3)$ \\
\hline Rehabilitation & $44(1.1)$ \\
\hline Surgical & $41(1.1)$ \\
\hline Veterans Affairs & $16(0.4)$ \\
\hline Women's & $5(0.1)$ \\
\hline Women's and Children's & $10(0.3)$ \\
\hline Total & 3,854 \\
\hline
\end{tabular}


D্

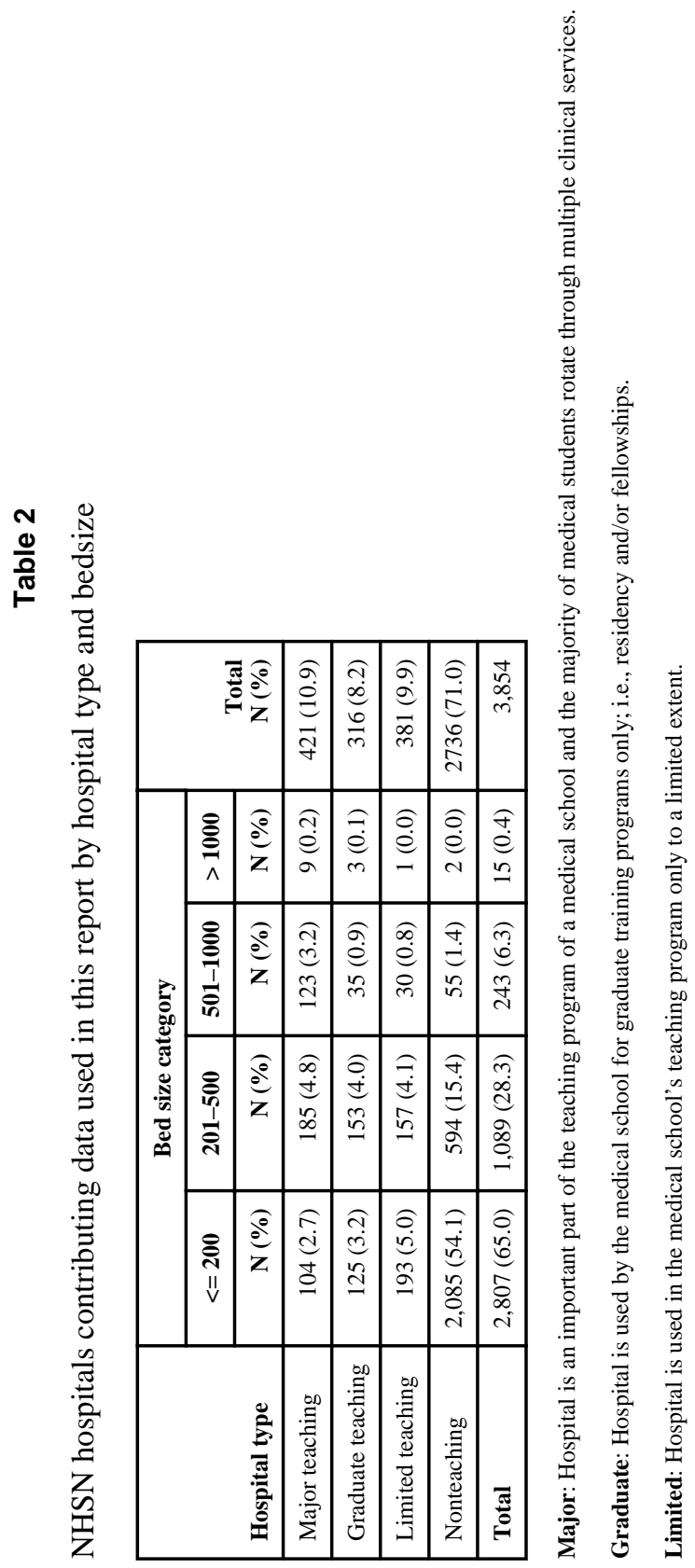

Am J Infect Control. Author manuscript; available in PMC 2015 October 29. 


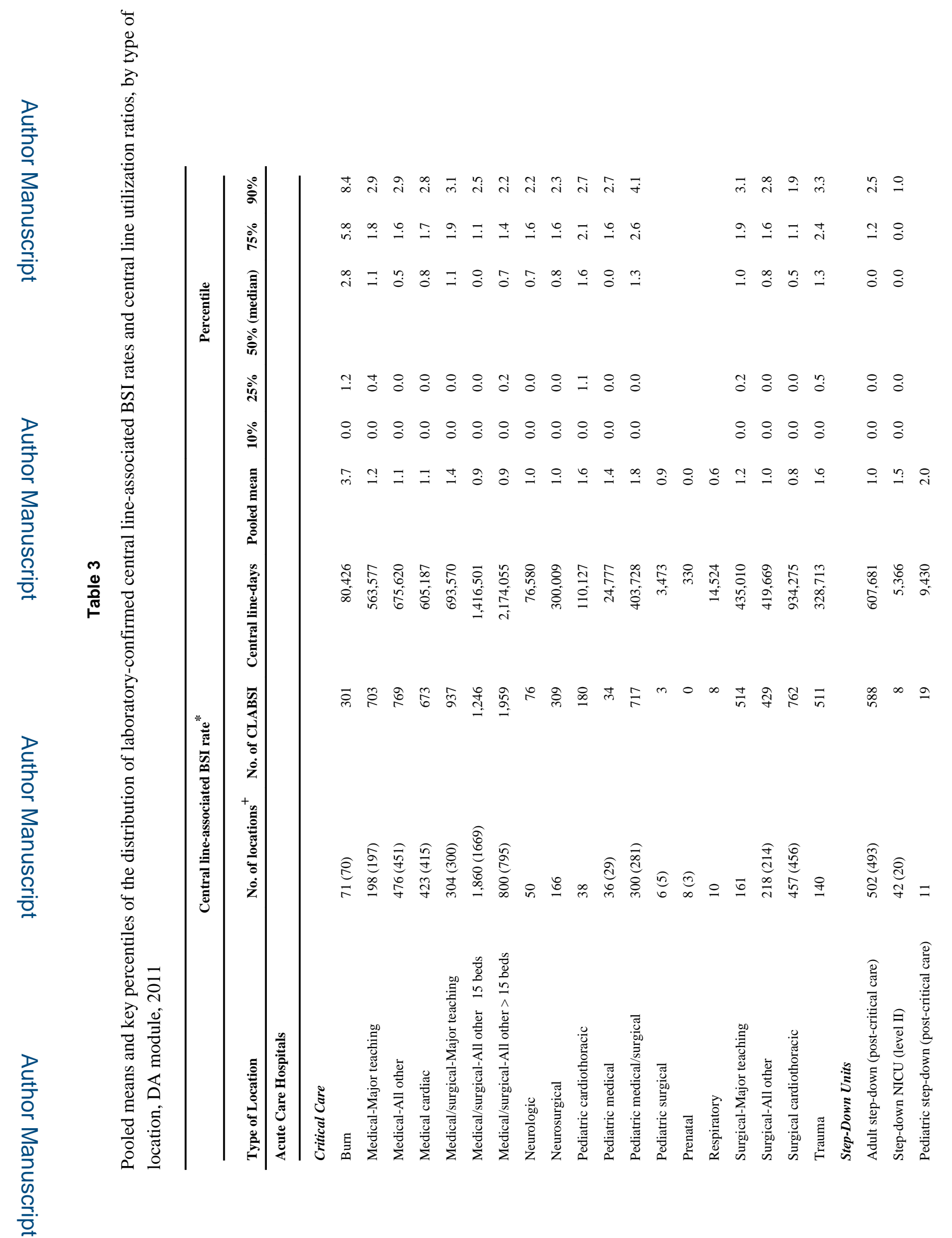

Am J Infect Control. Author manuscript; available in PMC 2015 October 29. 


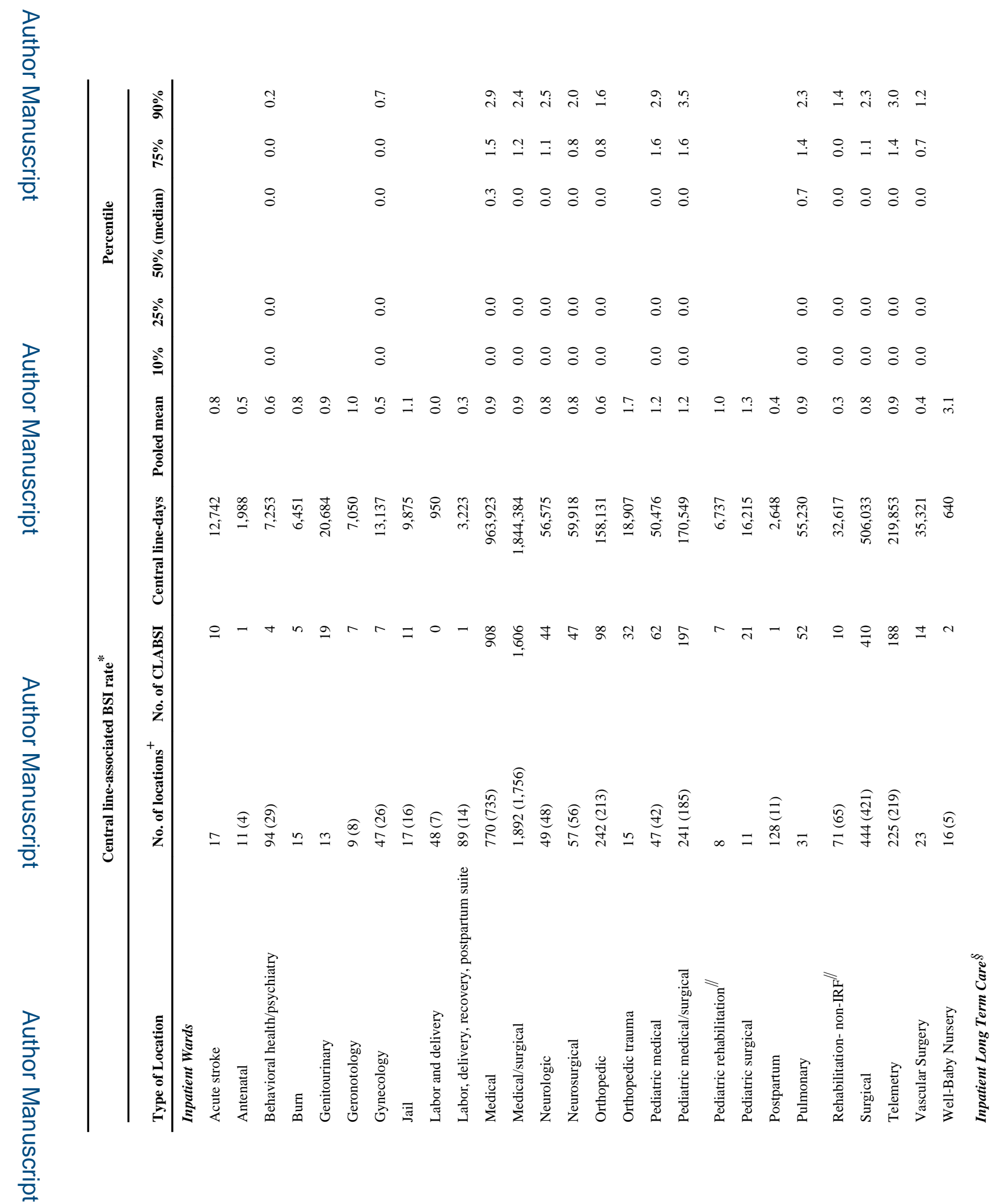

Am J Infect Control. Author manuscript; available in PMC 2015 October 29. 


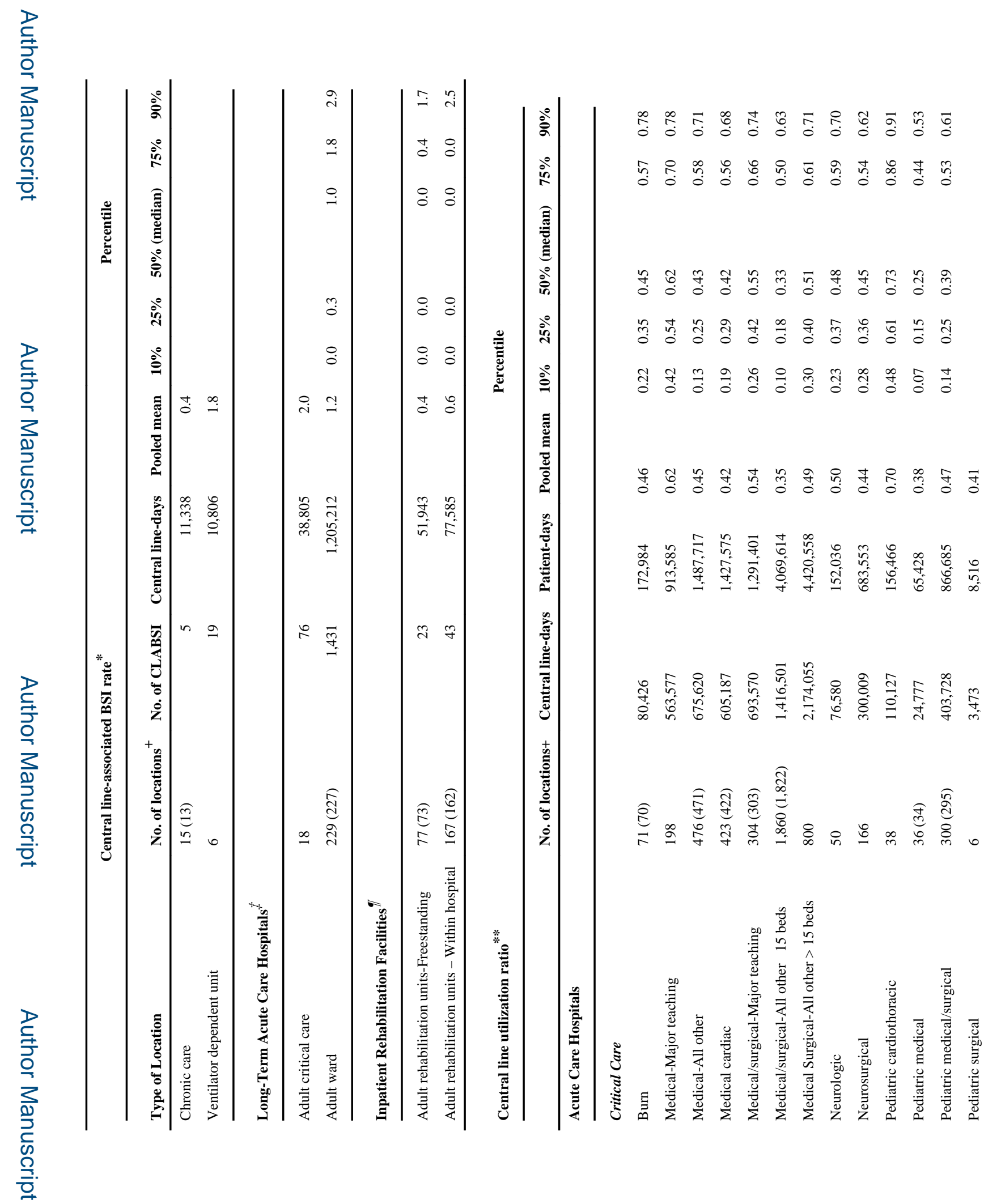

Am J Infect Control. Author manuscript; available in PMC 2015 October 29. 


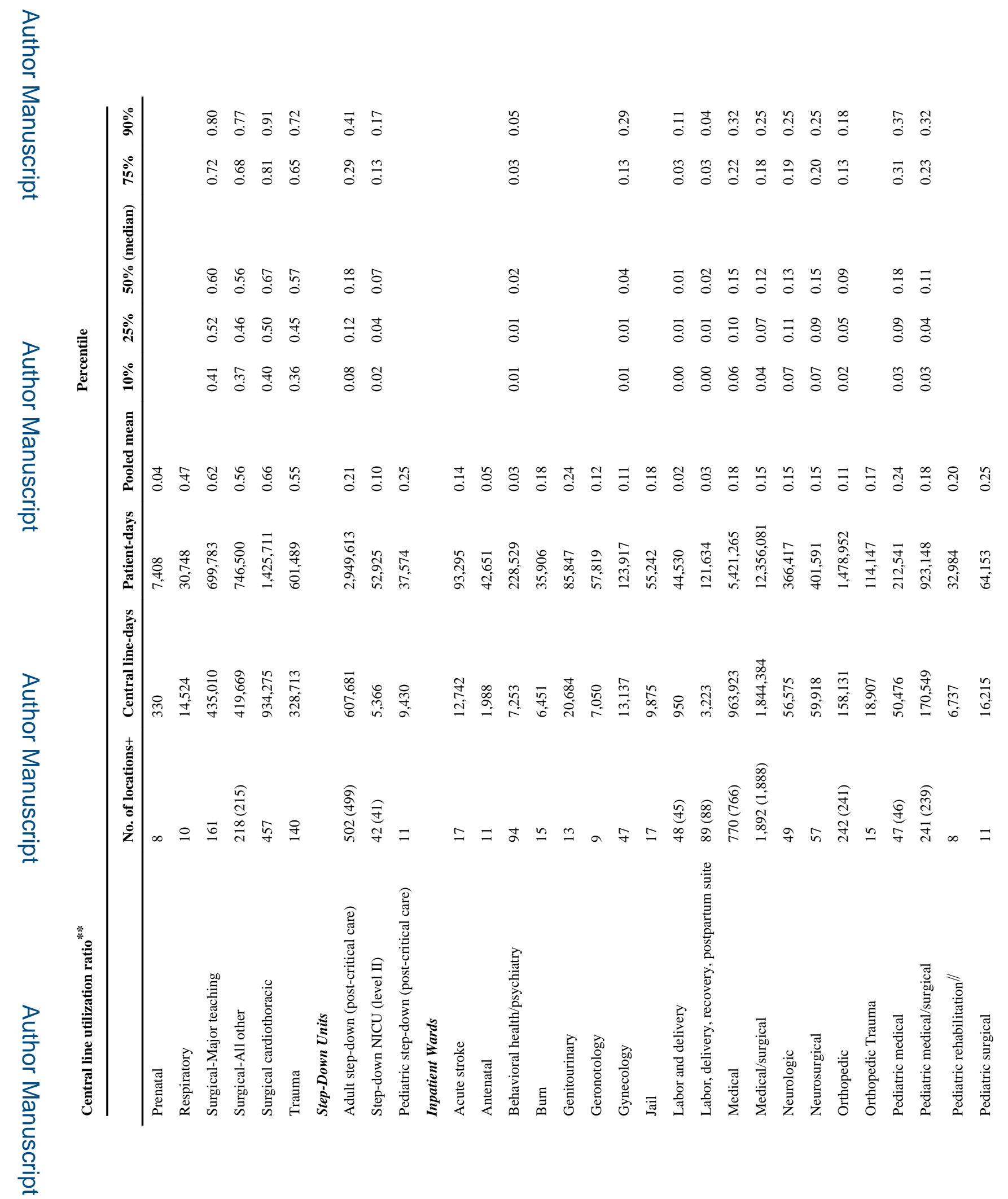

Am J Infect Control. Author manuscript; available in PMC 2015 October 29. 


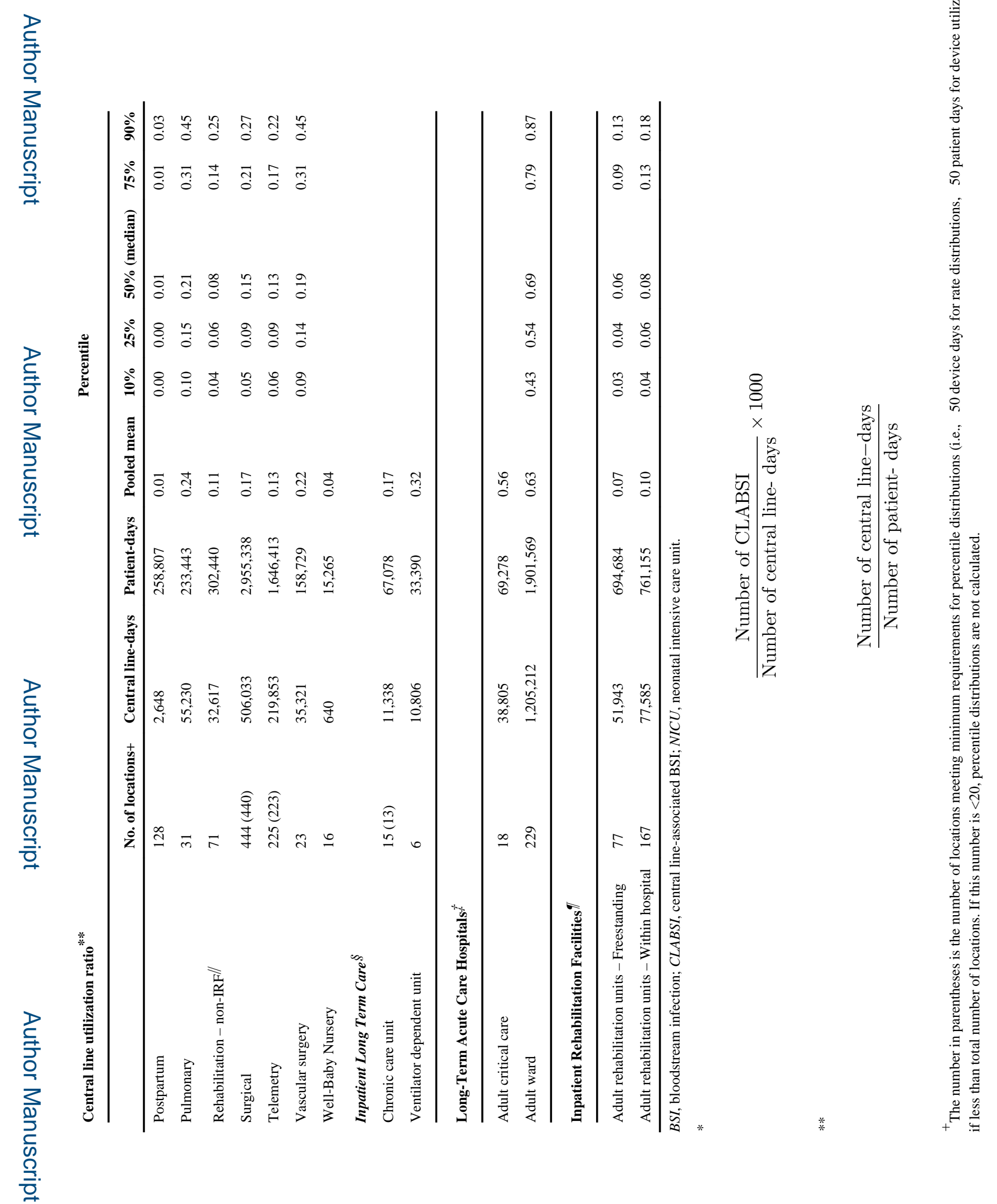




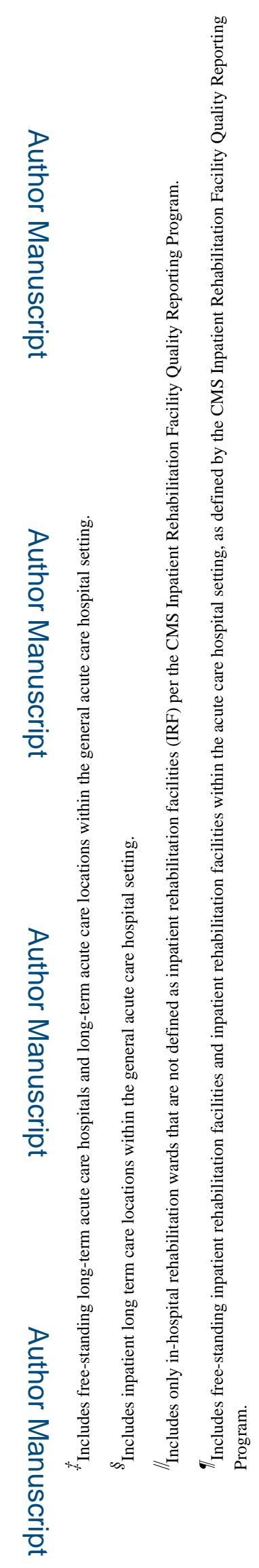

Am J Infect Control. Author manuscript; available in PMC 2015 October 29. 


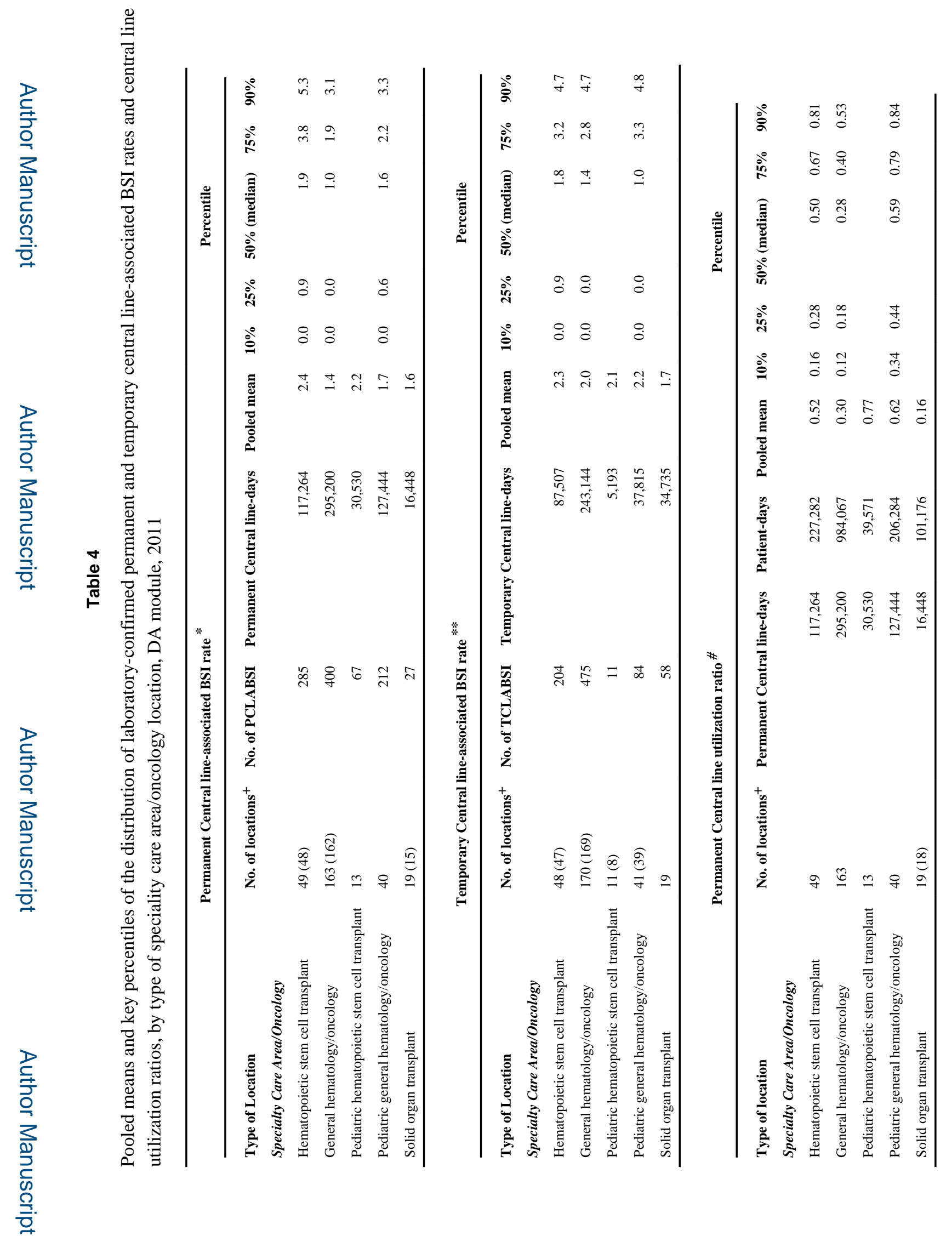

Am J Infect Control. Author manuscript; available in PMC 2015 October 29. 


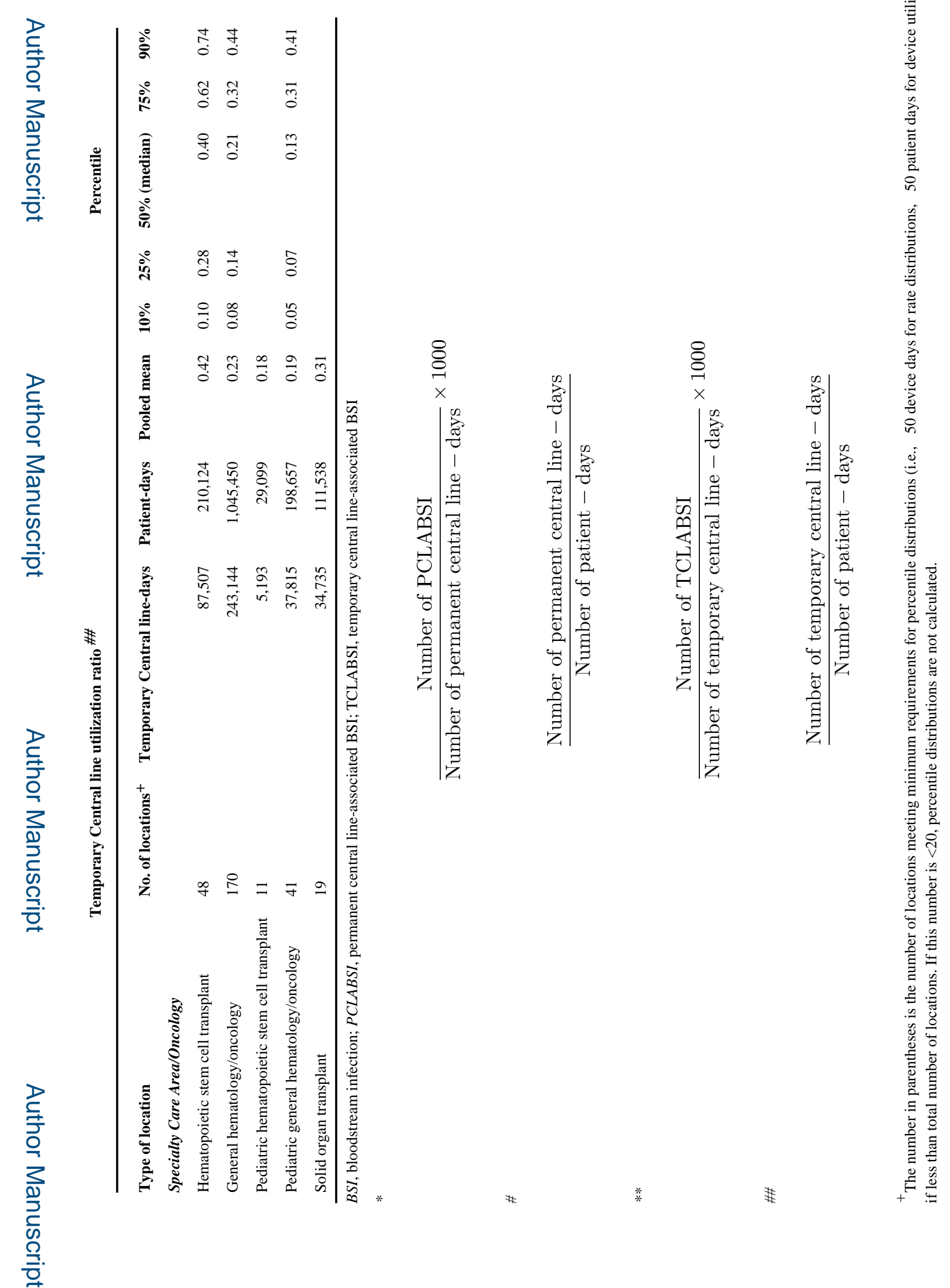




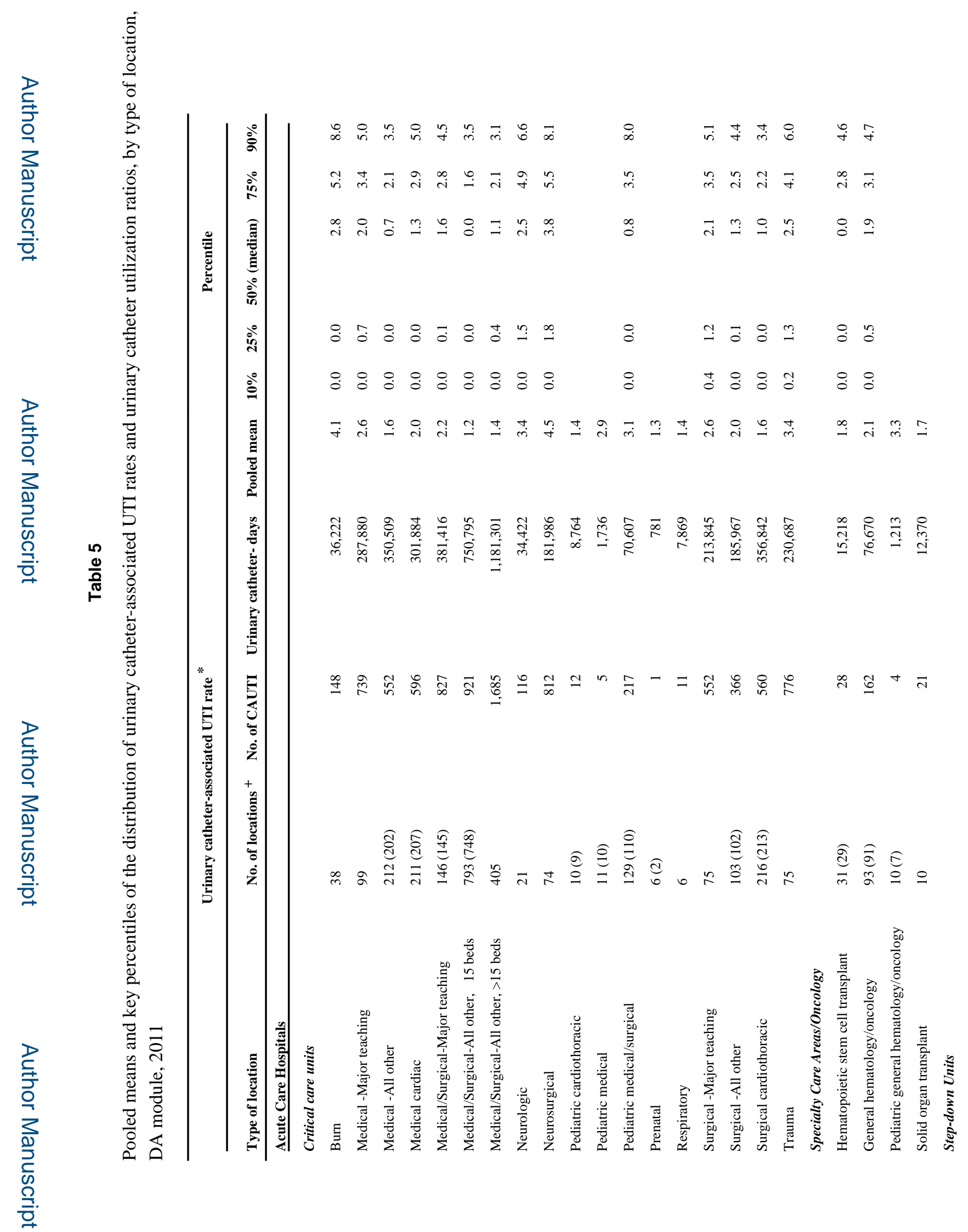

Am J Infect Control. Author manuscript; available in PMC 2015 October 29. 
Dudeck et al.

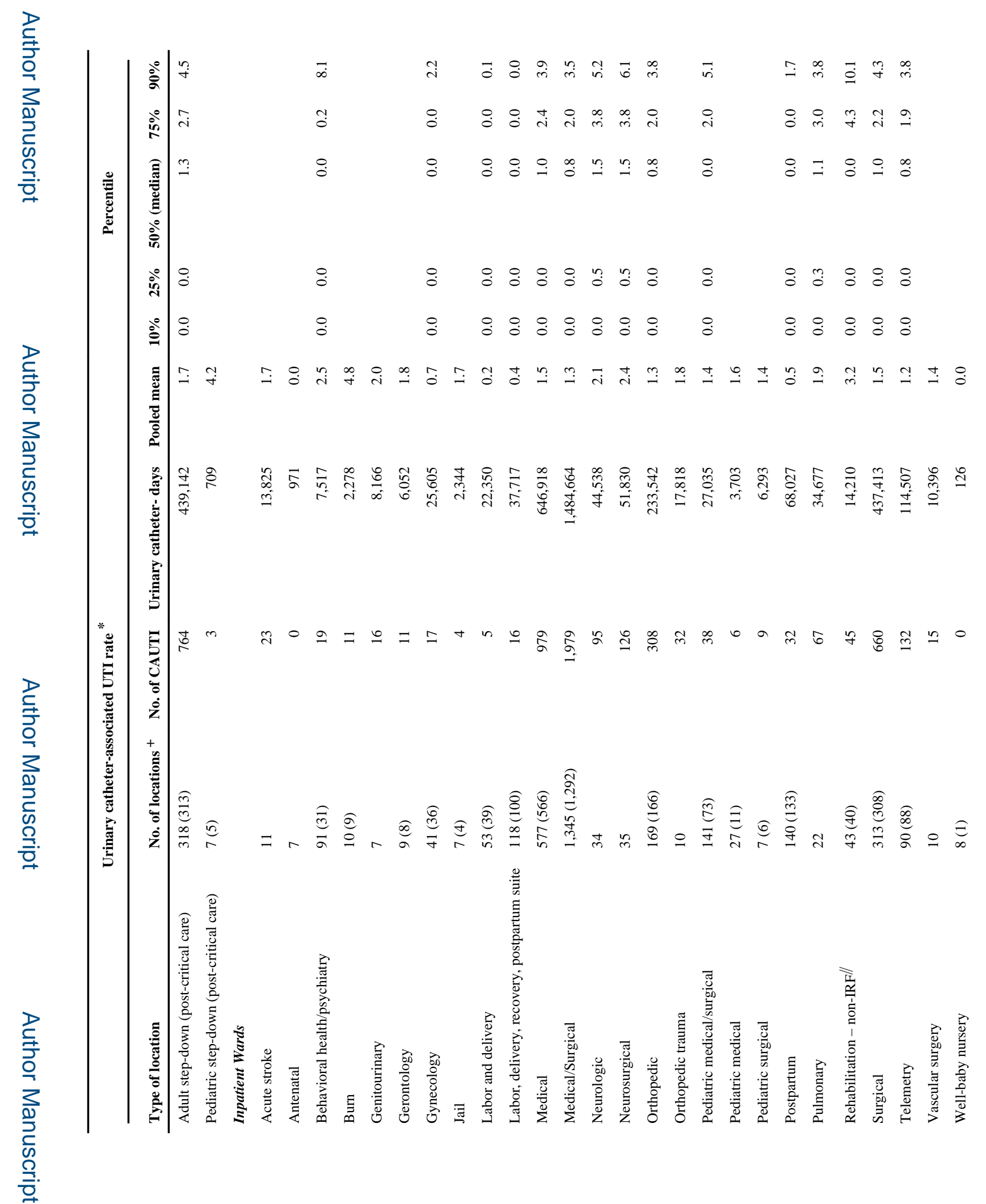

Am J Infect Control. Author manuscript; available in PMC 2015 October 29. 


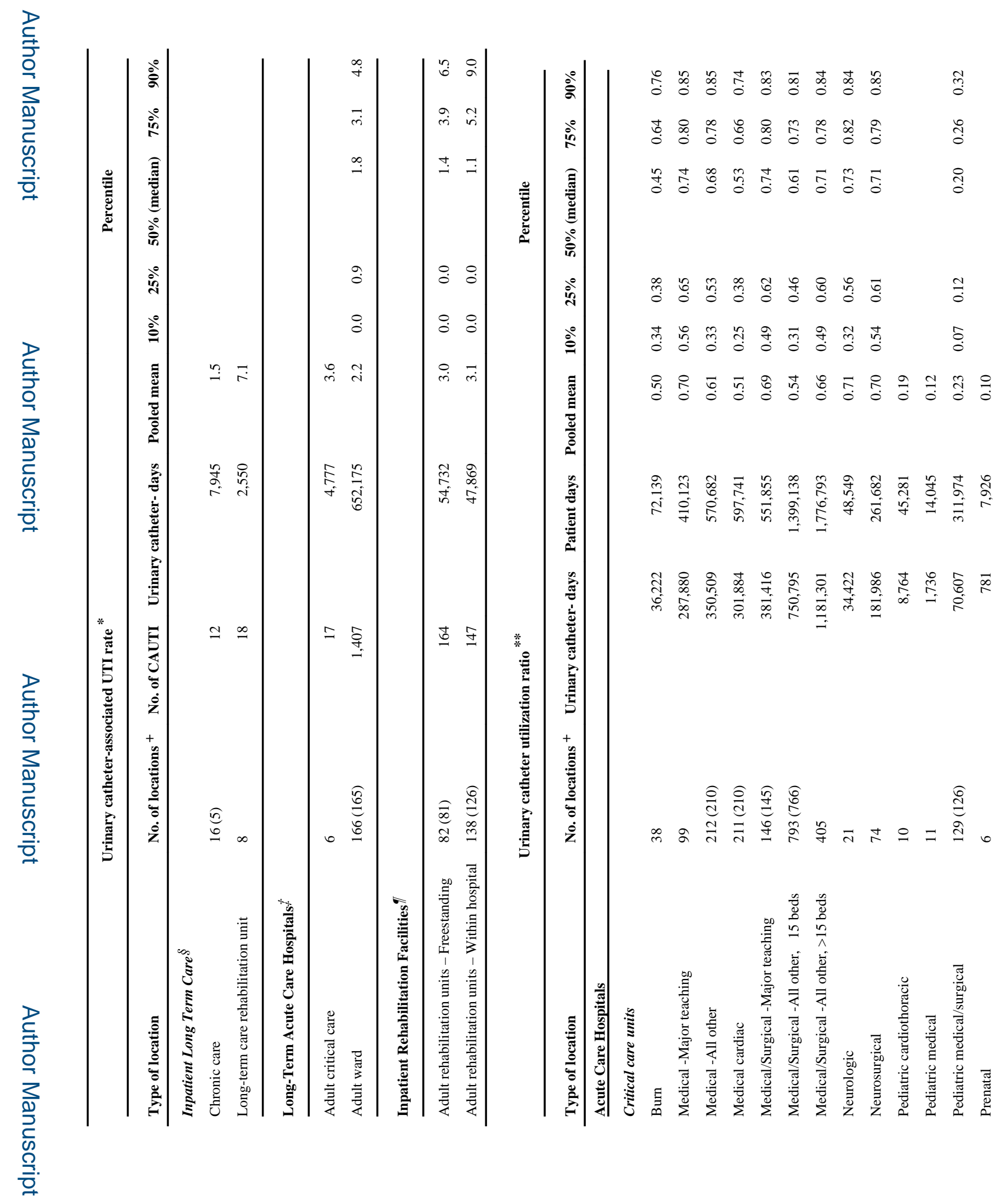

Am J Infect Control. Author manuscript; available in PMC 2015 October 29. 


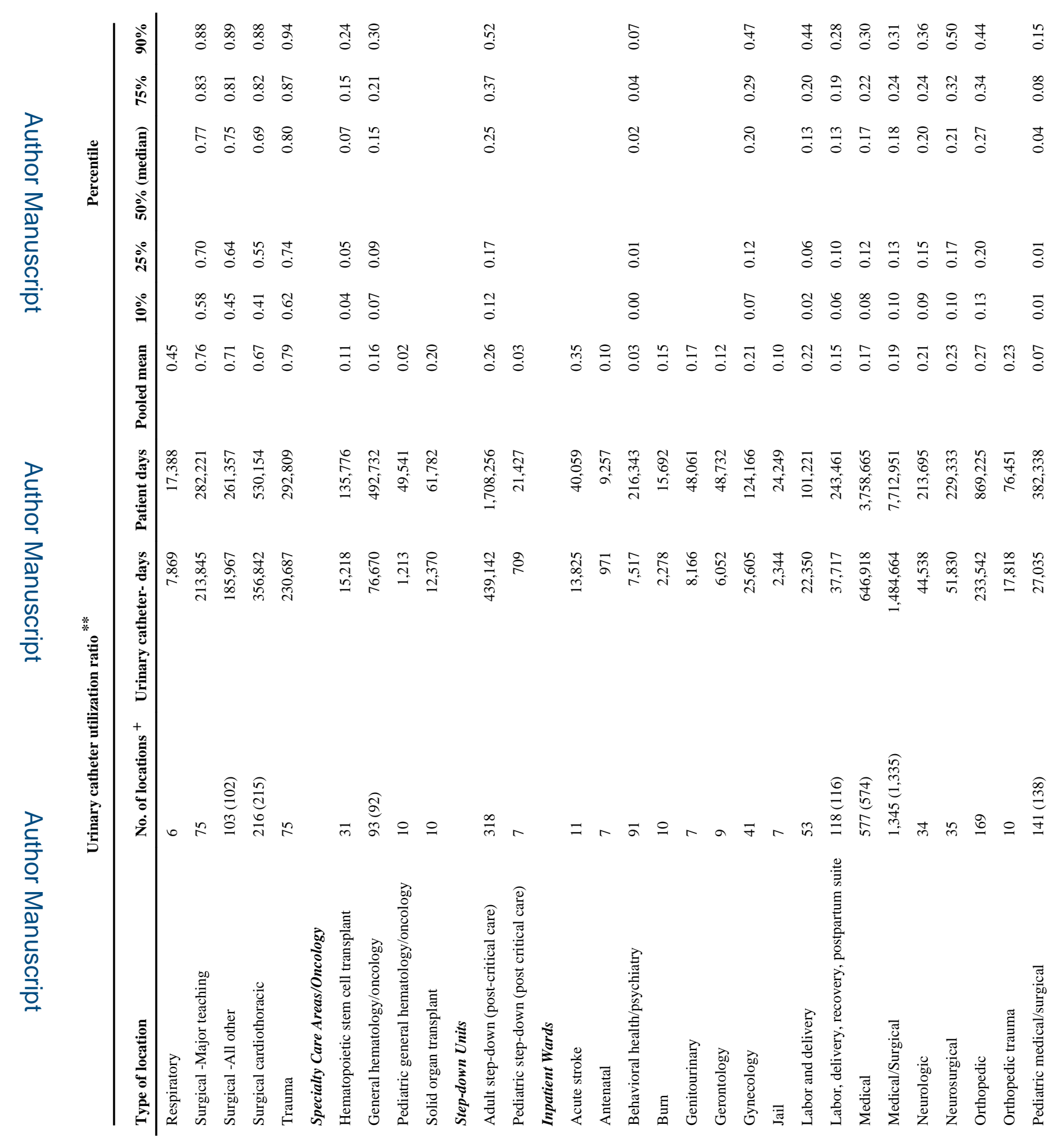

를 
Dudeck et al.

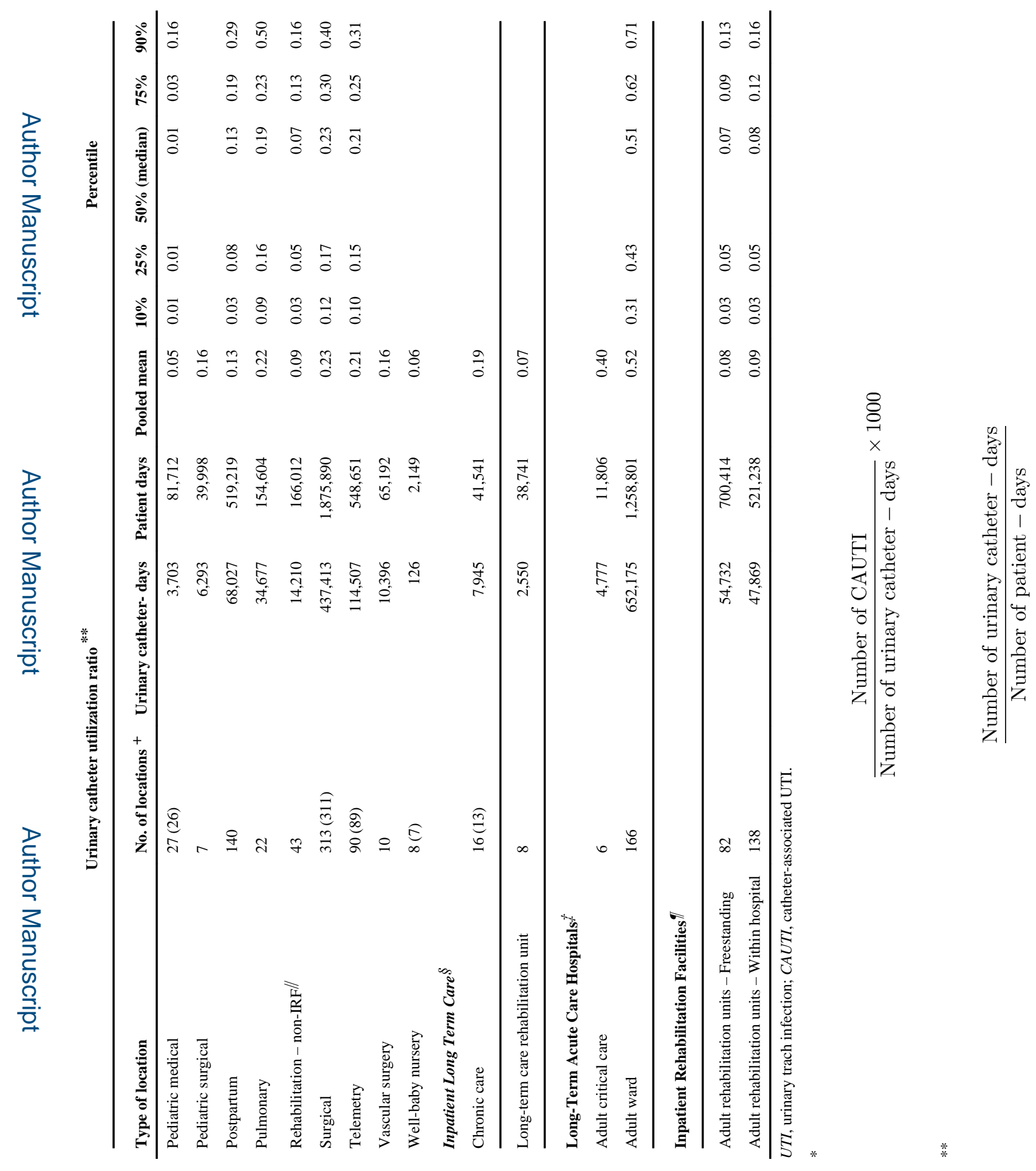

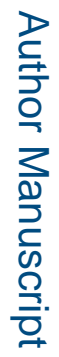




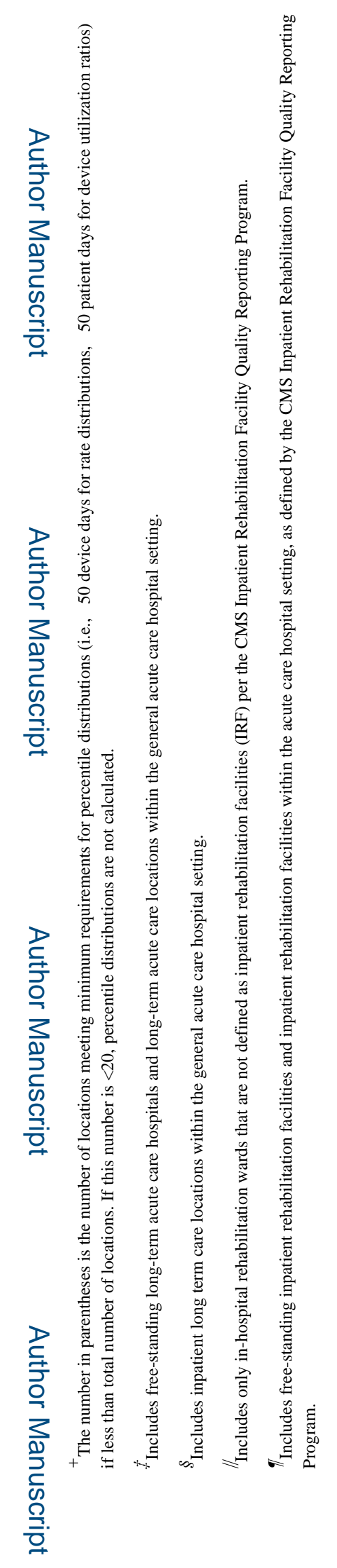

Am J Infect Control. Author manuscript; available in PMC 2015 October 29. 


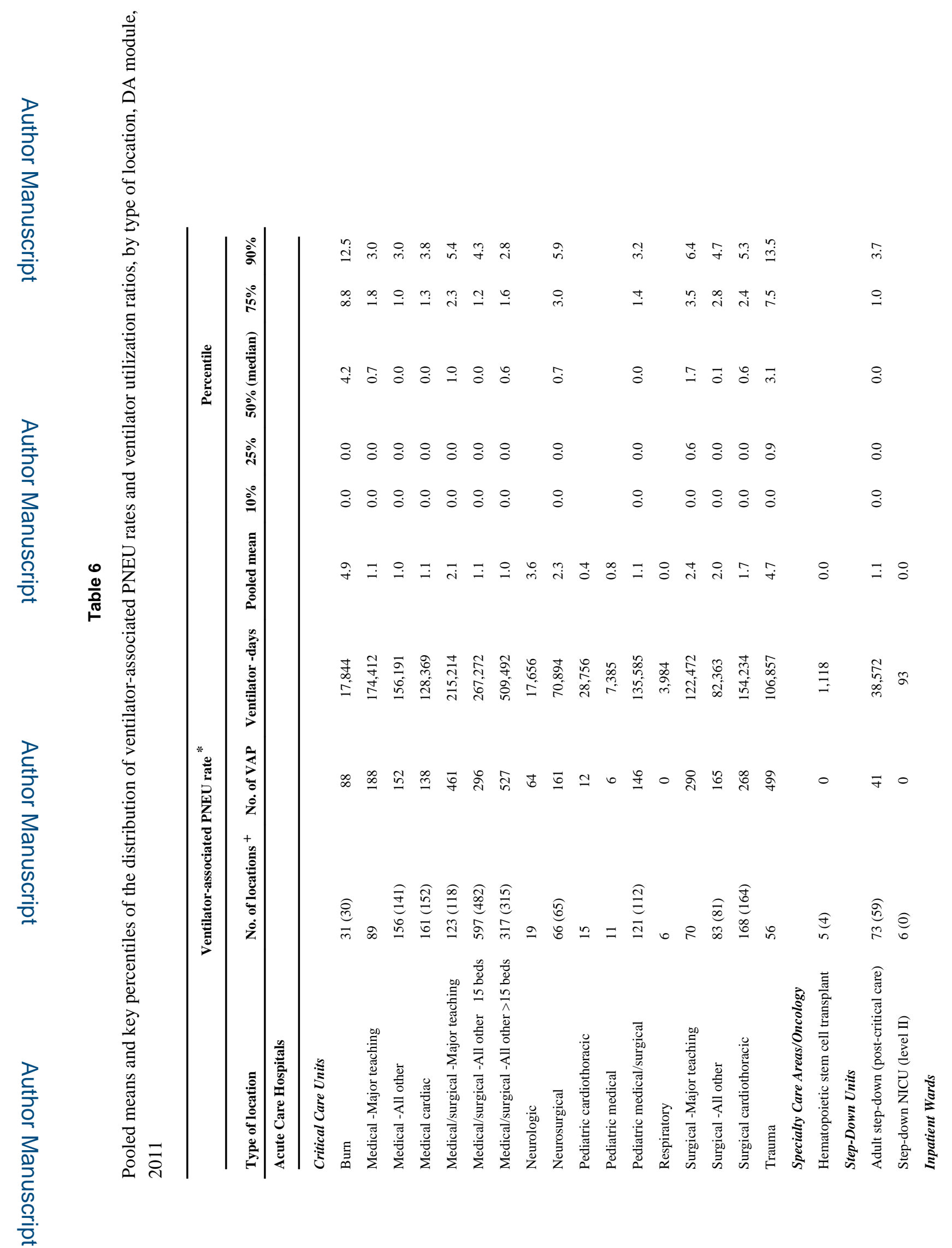

Am J Infect Control. Author manuscript; available in PMC 2015 October 29. 


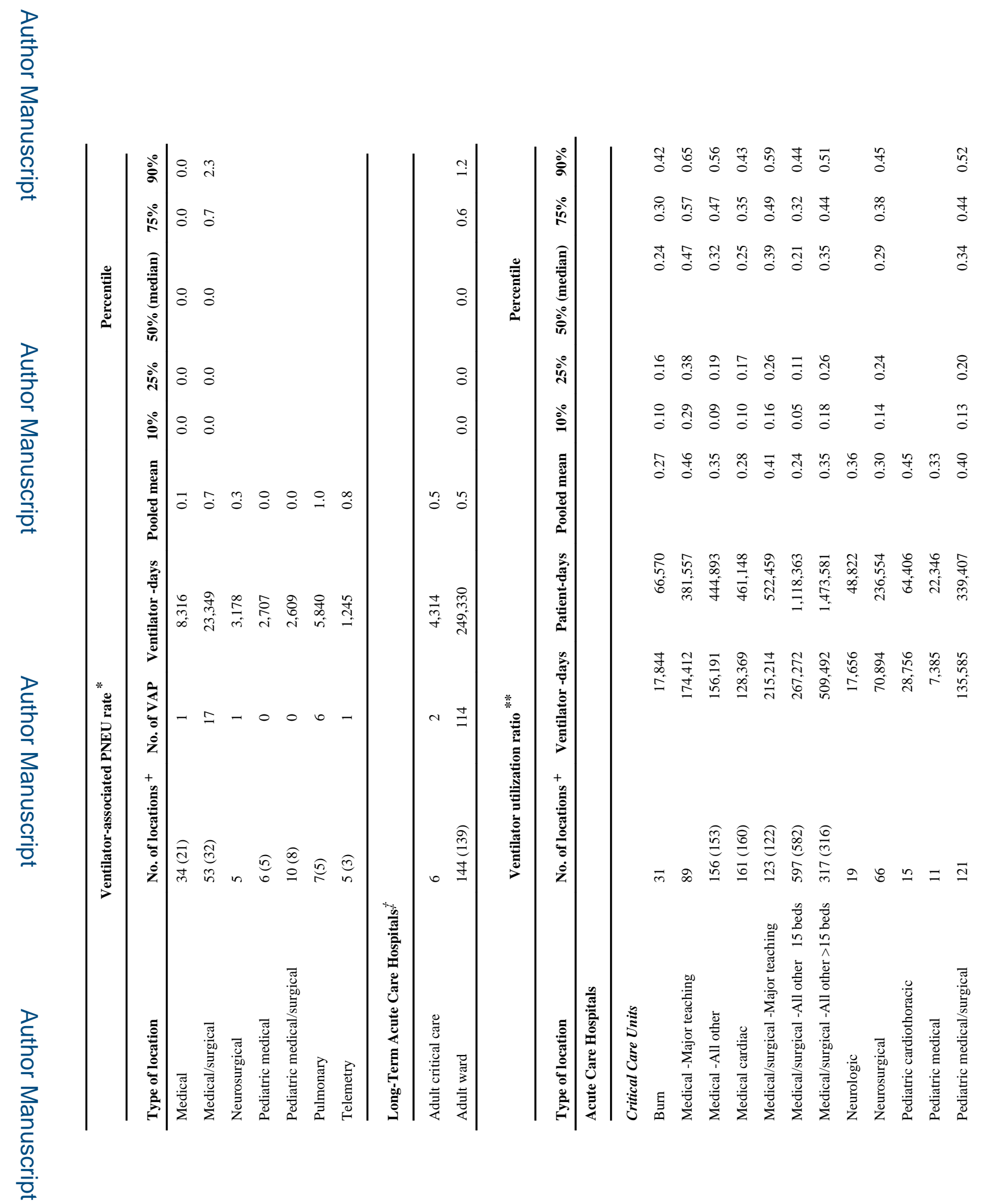

Am J Infect Control. Author manuscript; available in PMC 2015 October 29. 


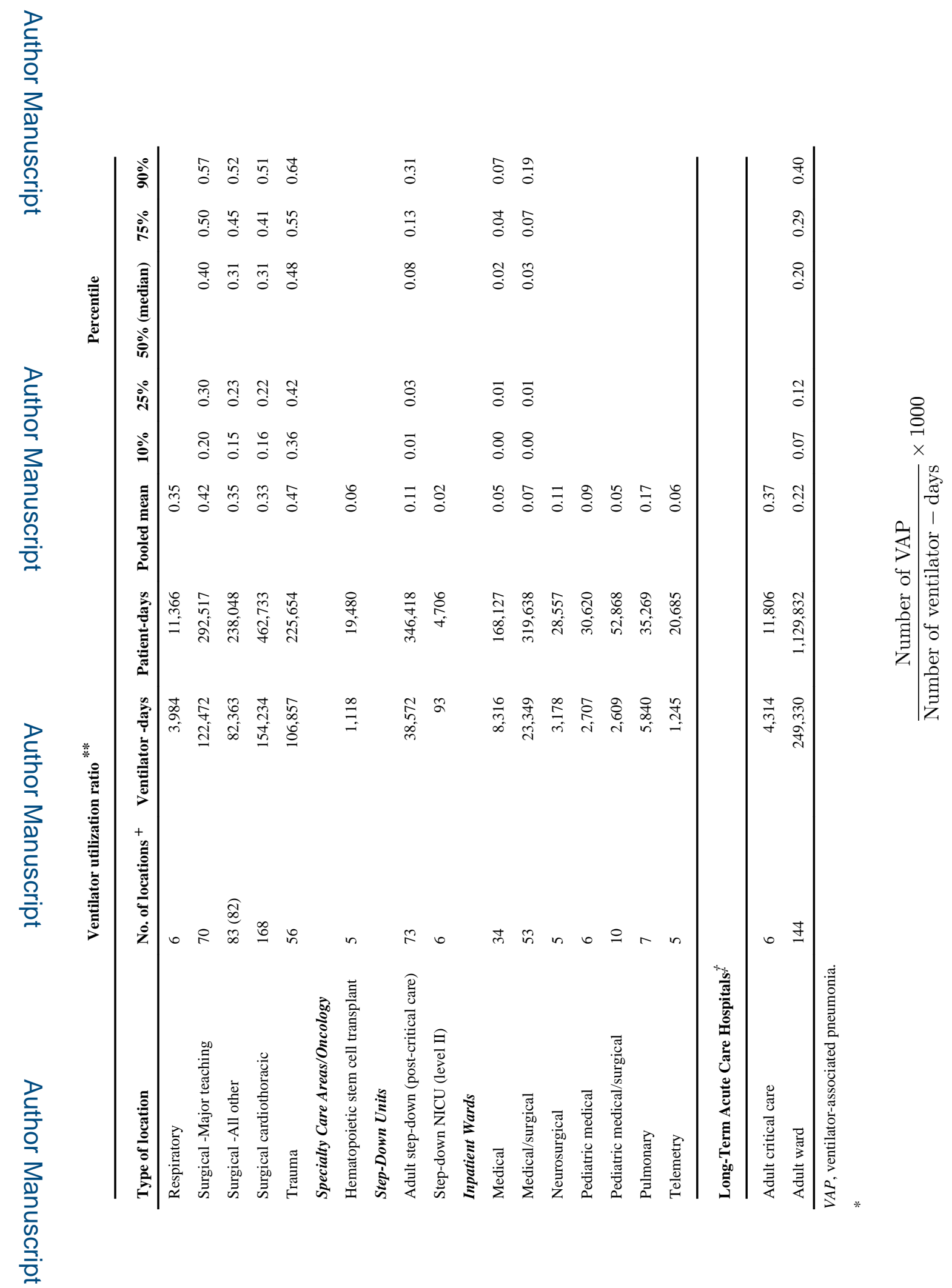

Am J Infect Control. Author manuscript; available in PMC 2015 October 29. 


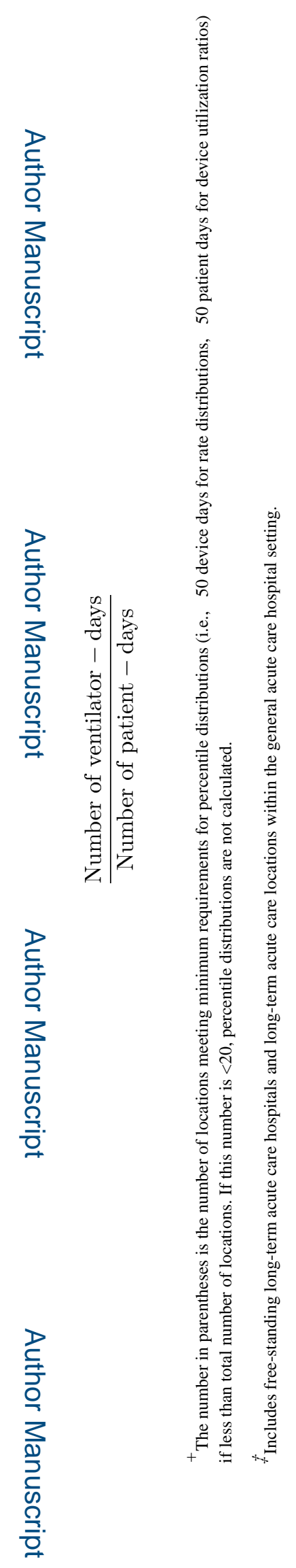

Am J Infect Control. Author manuscript; available in PMC 2015 October 29. 
Dudeck et al.

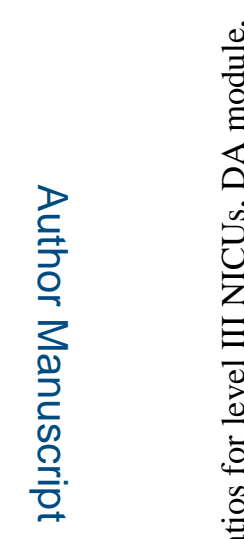

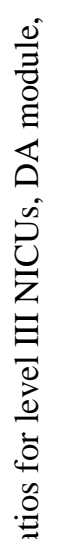

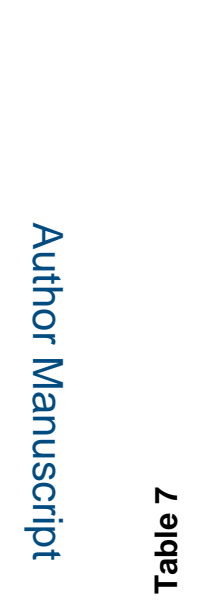

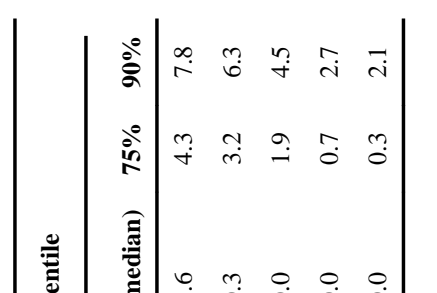

|

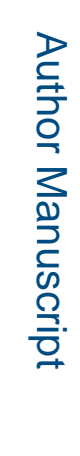

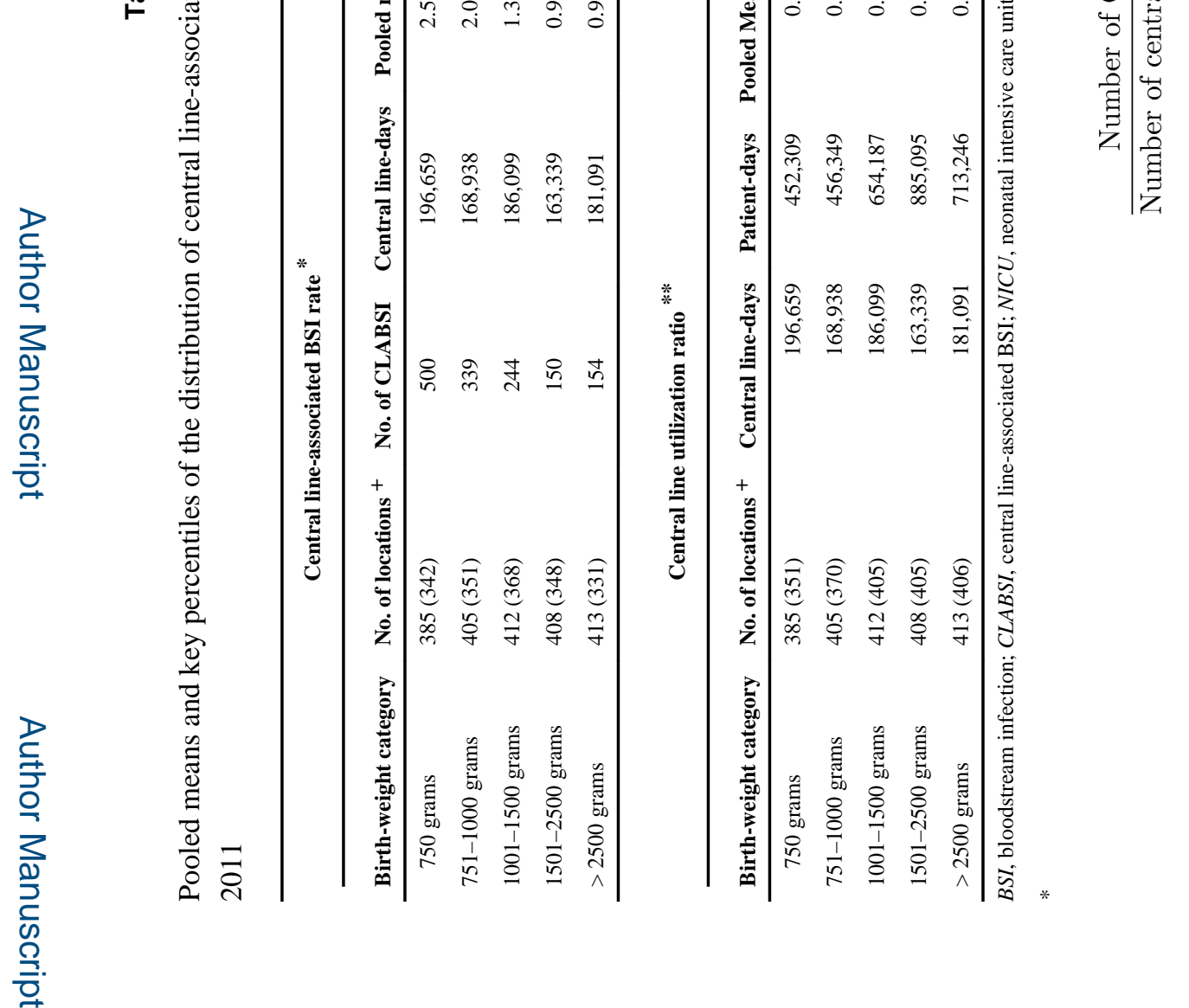

Am J Infect Control. Author manuscript; available in PMC 2015 October 29. 


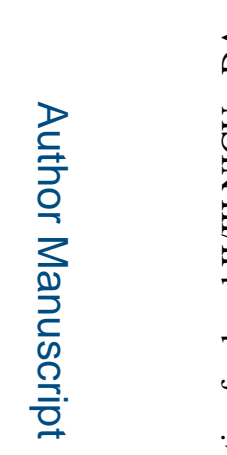

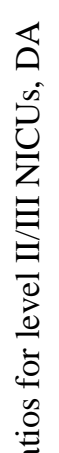

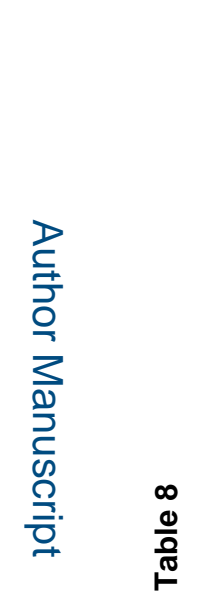

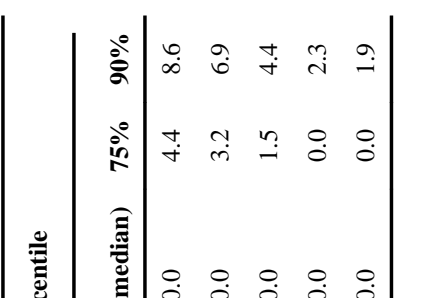

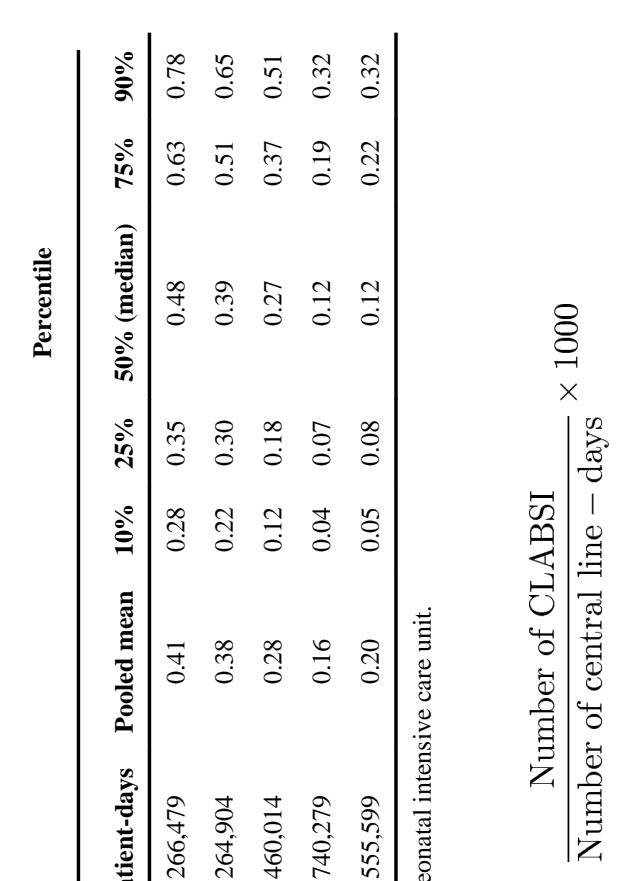

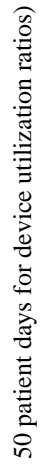

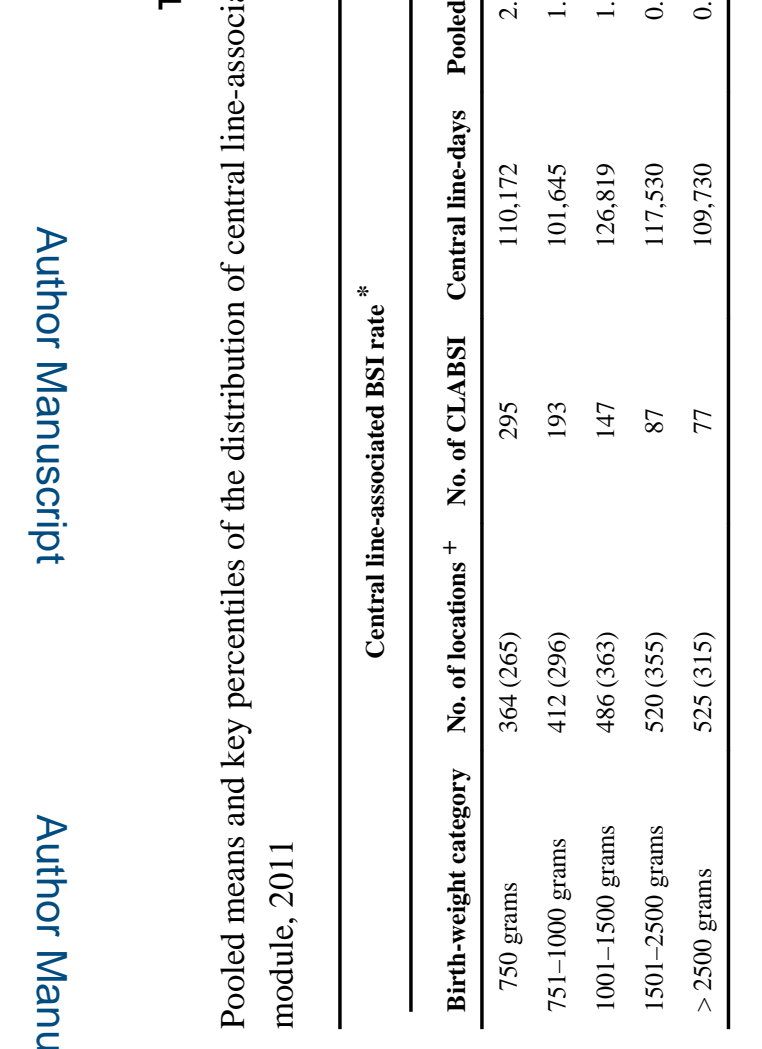

*..

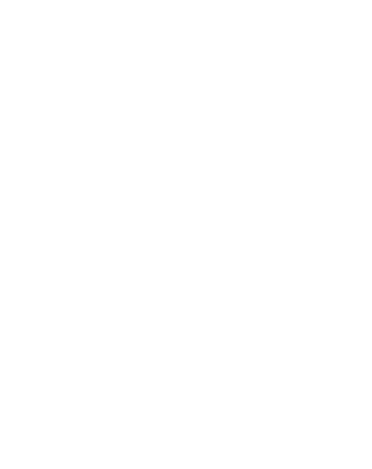

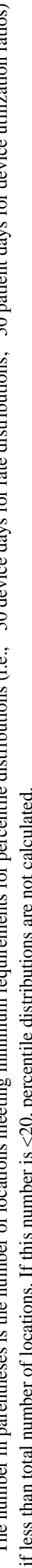

올.

Am J Infect Control. Author manuscript; available in PMC 2015 October 29. 

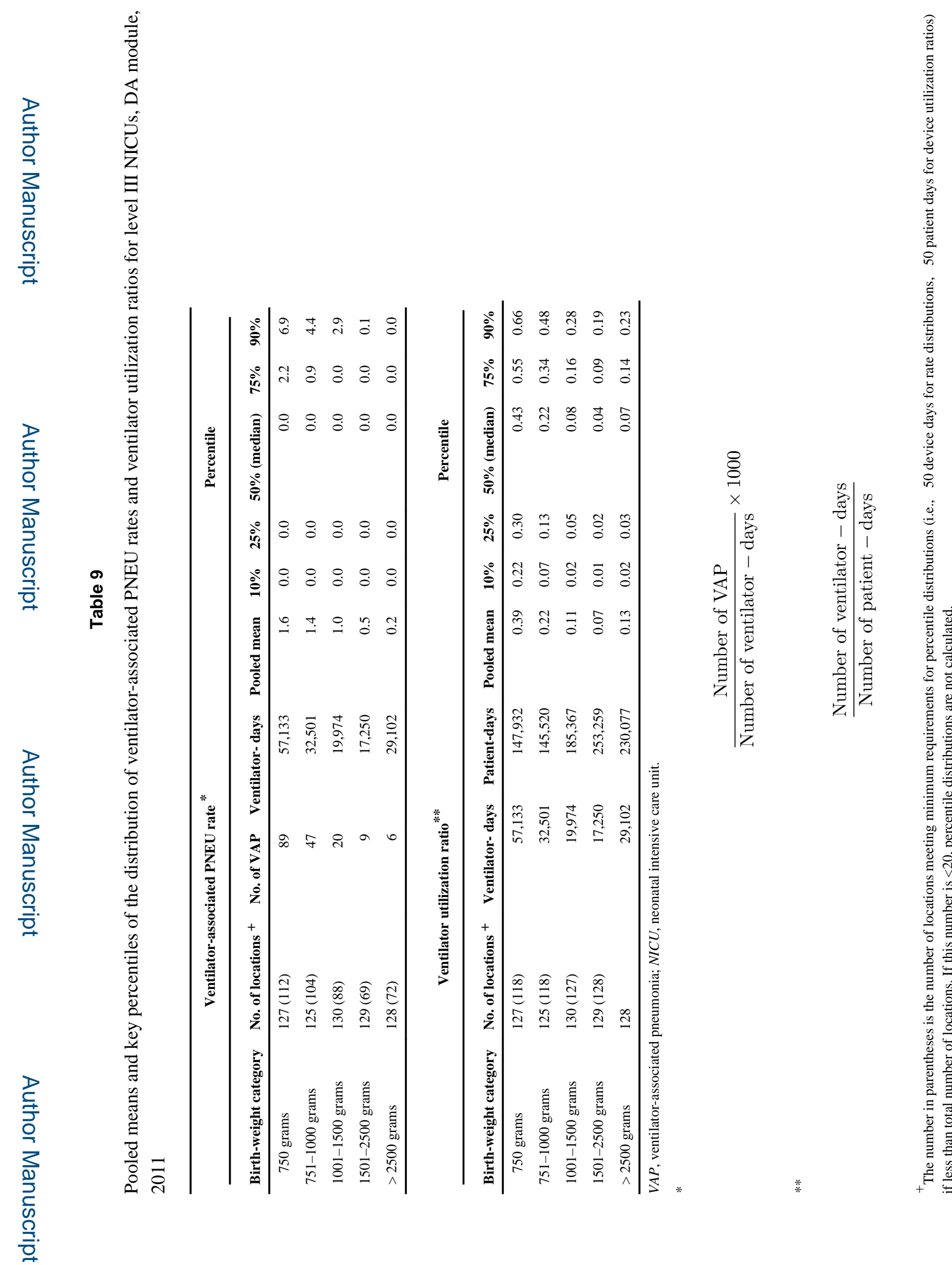


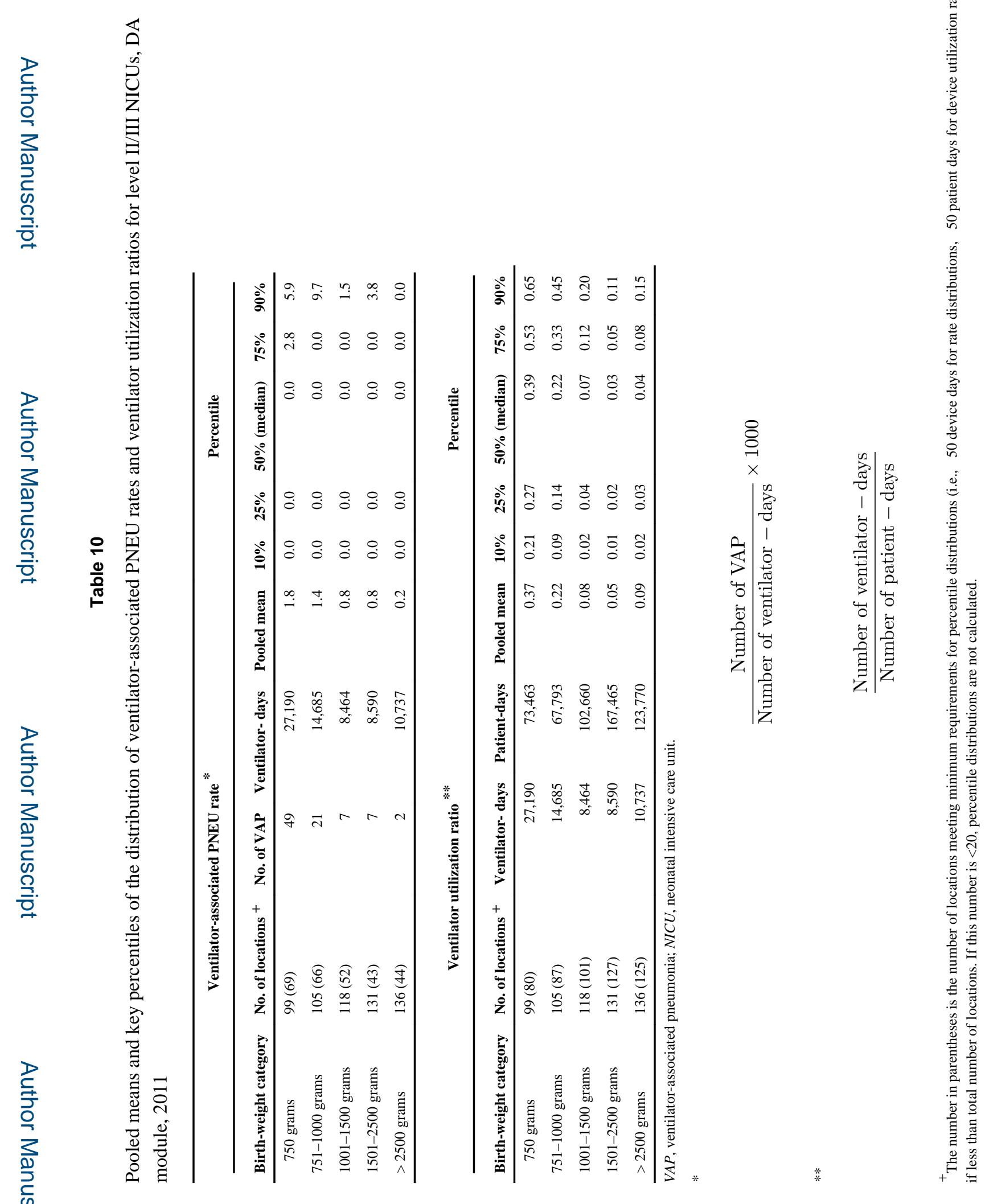




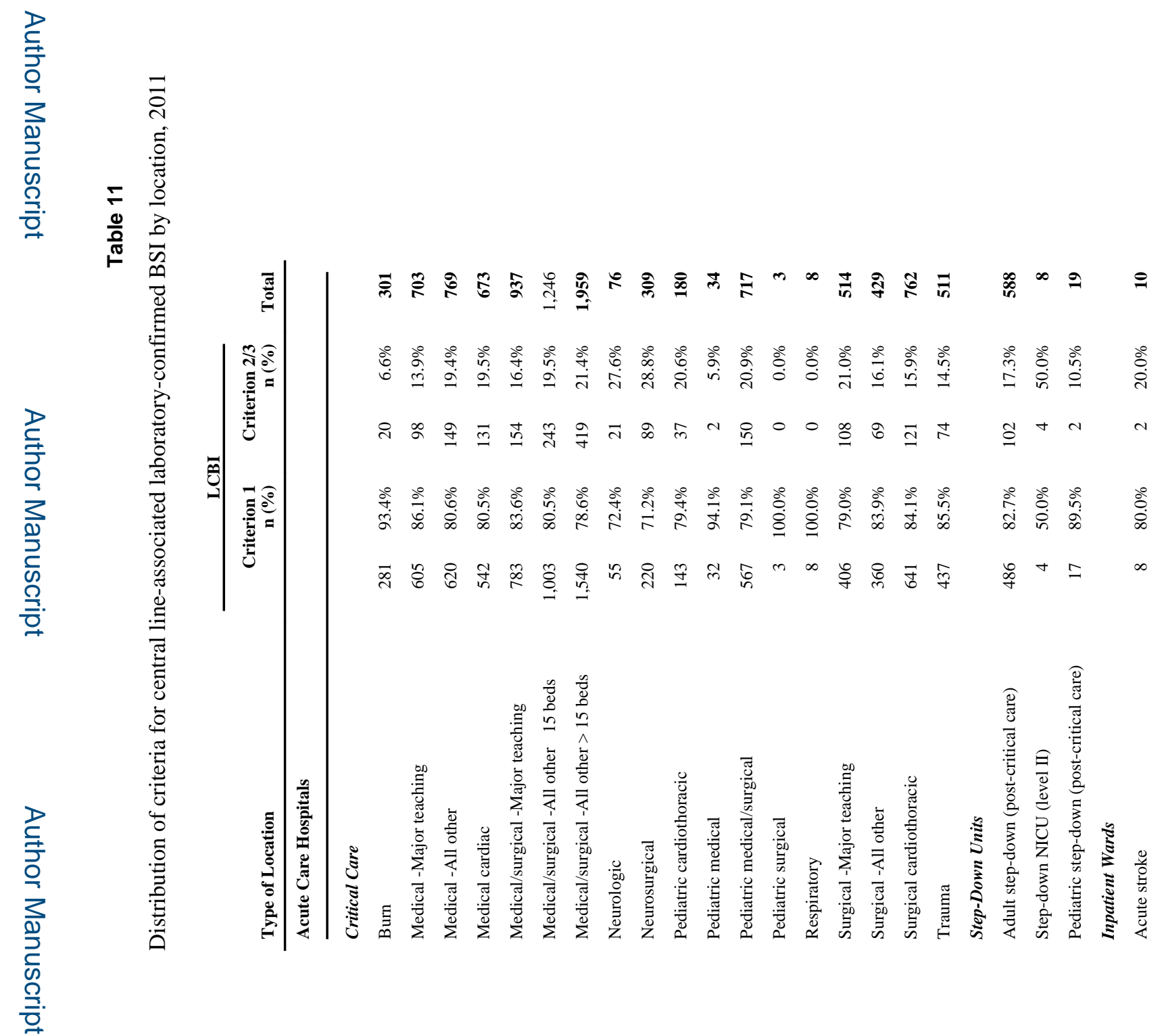

Am J Infect Control. Author manuscript; available in PMC 2015 October 29. 


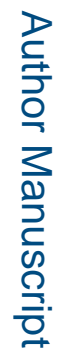

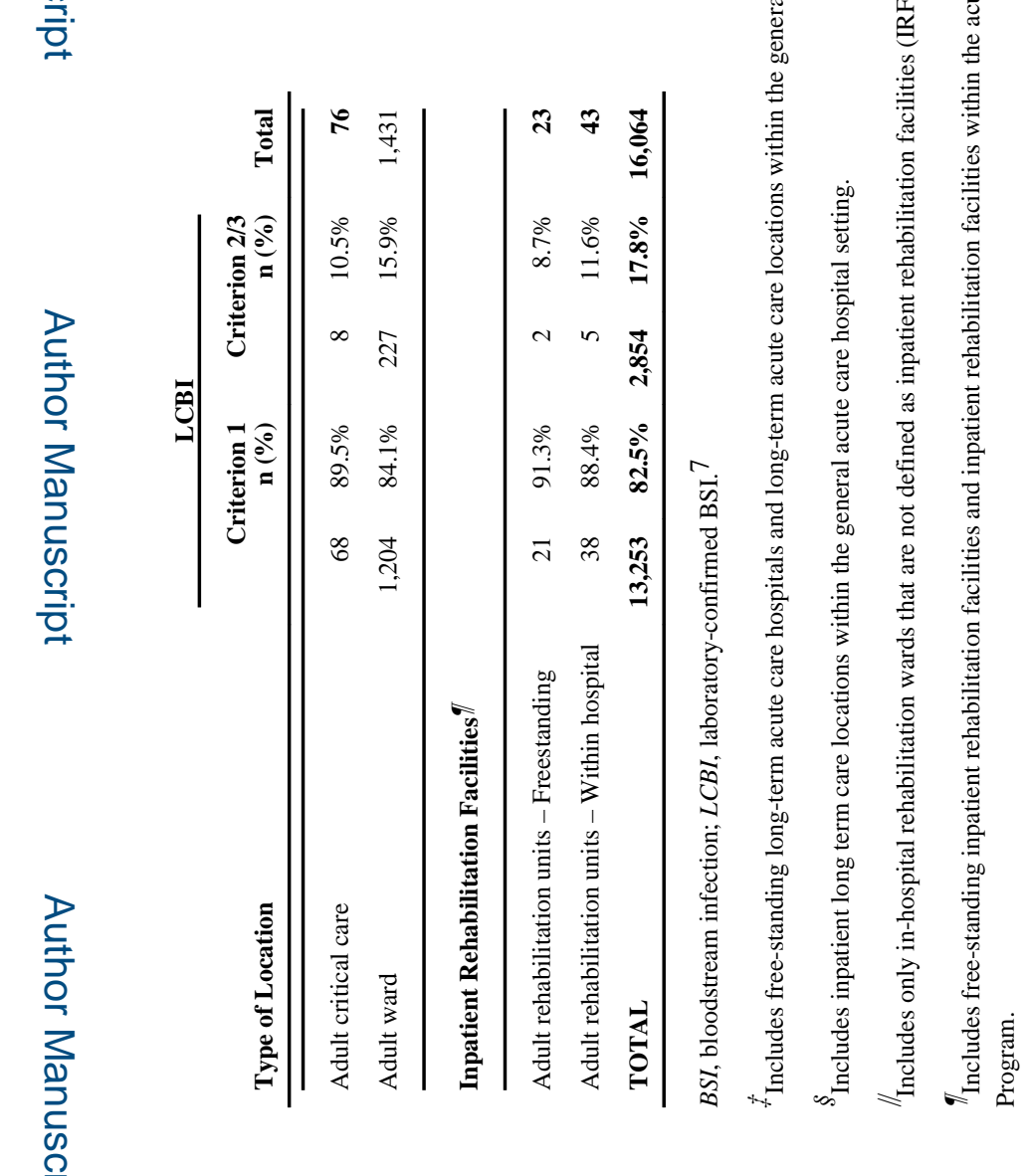




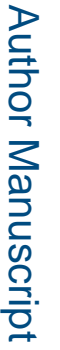

롱

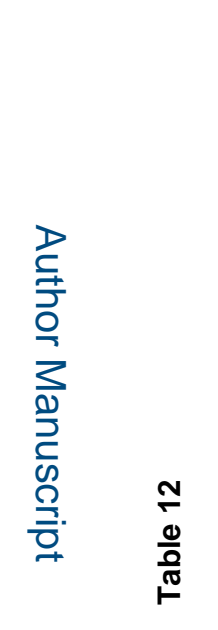

.ี

근

$\overline{\tilde{n}}$

㟒

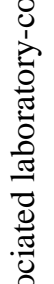$$
\text { 衰 }
$$

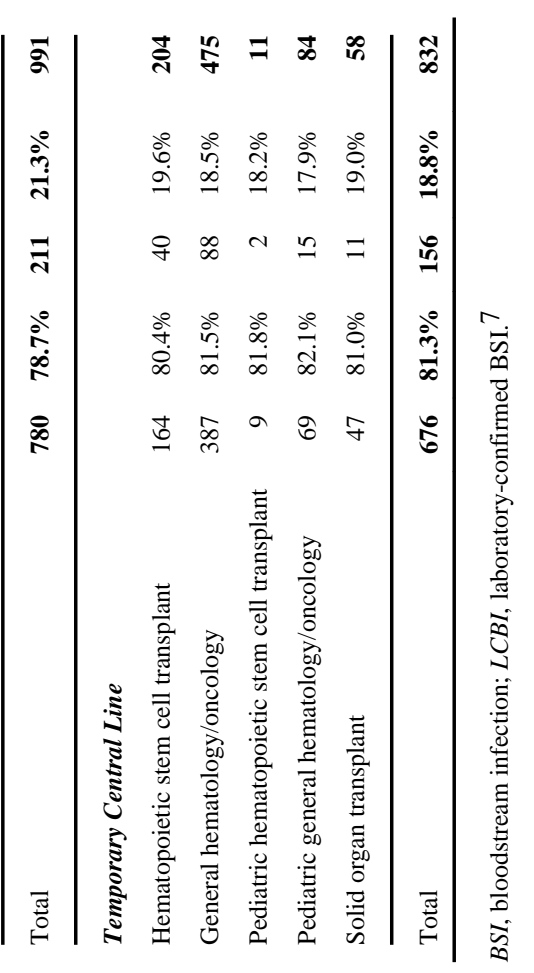

Am J Infect Control. Author manuscript; available in PMC 2015 October 29. 


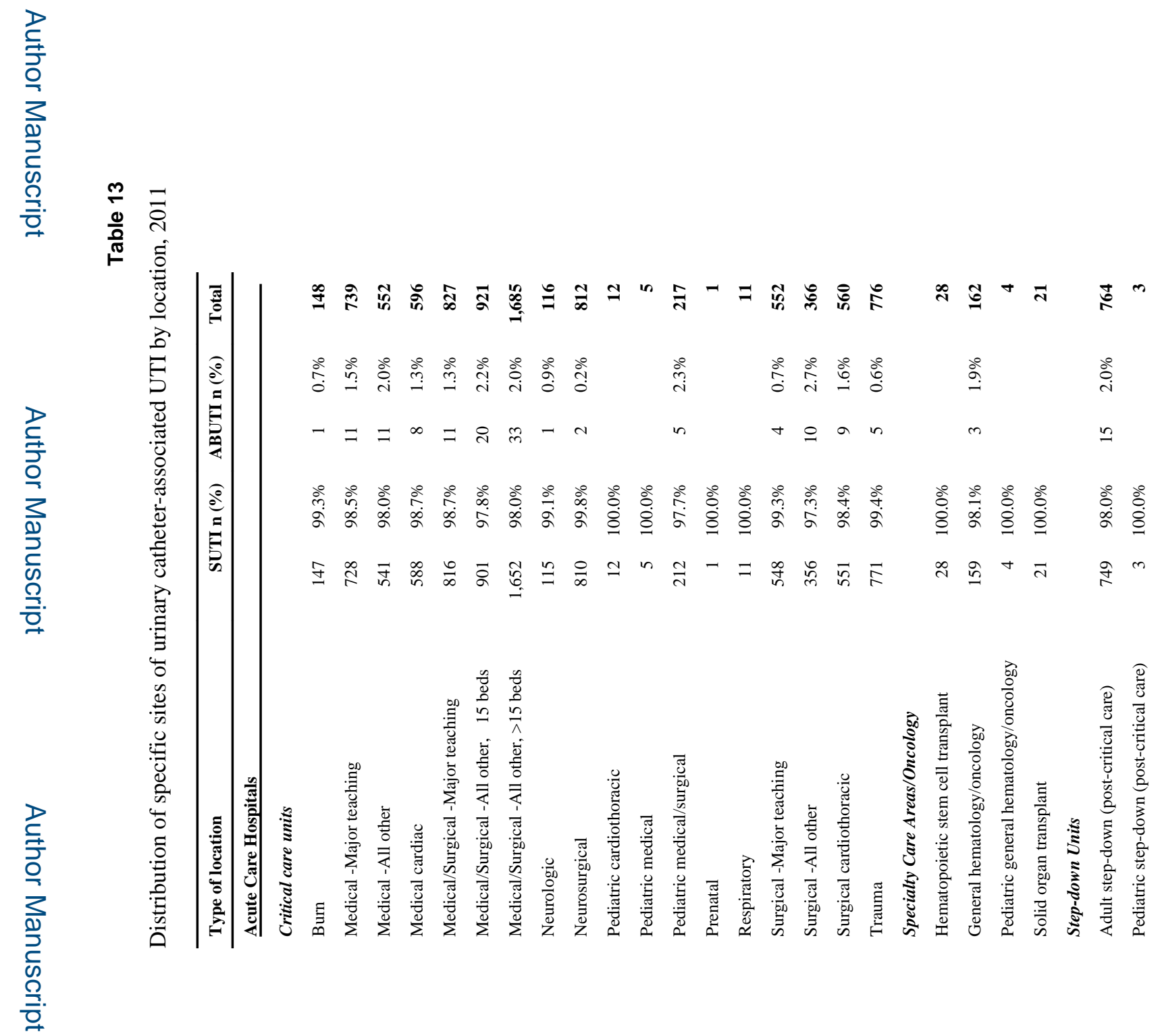

Am J Infect Control. Author manuscript; available in PMC 2015 October 29. 


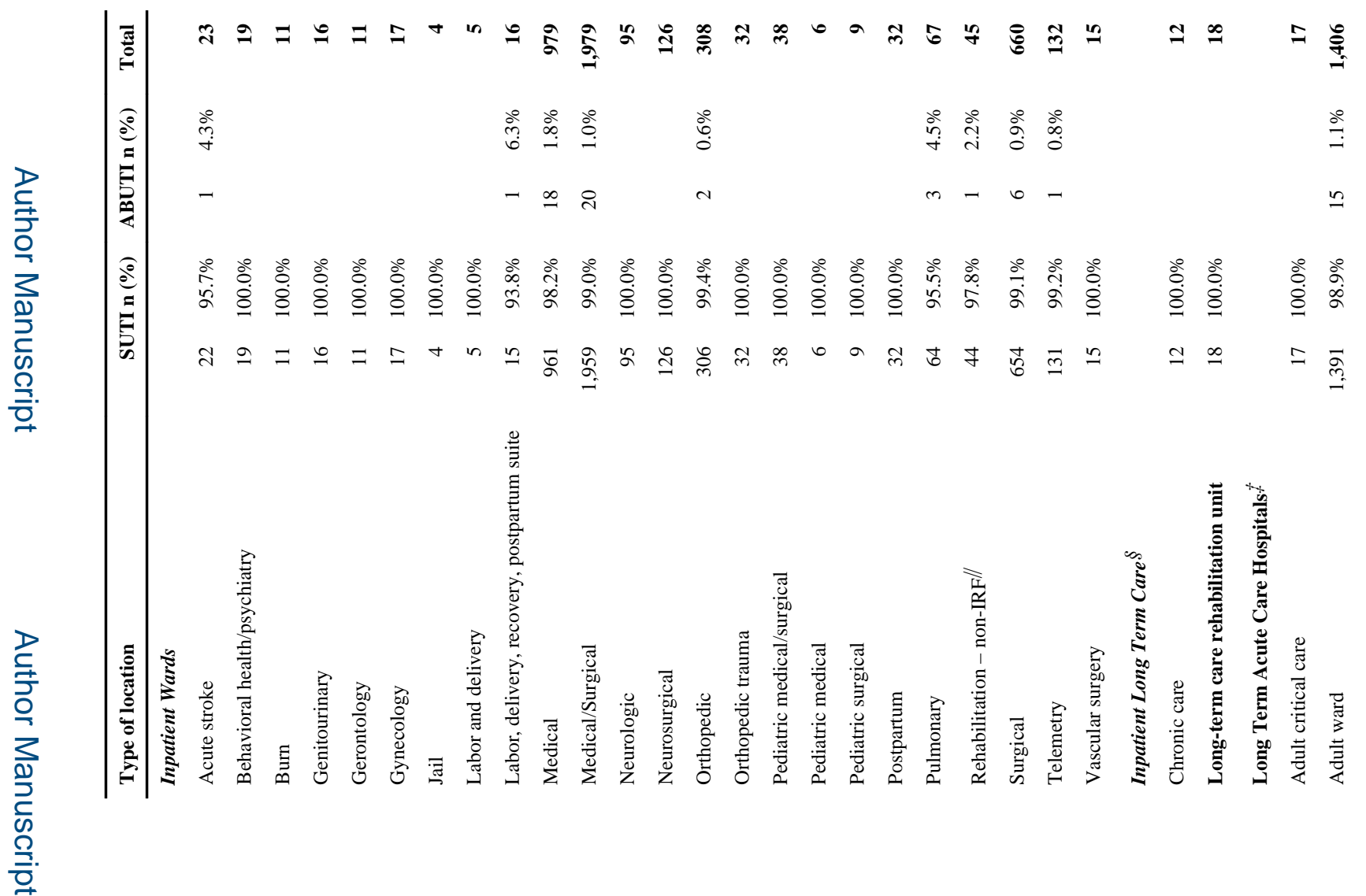
Am J Infect Control. Author manuscript; available in PMC 2015 October 29. 


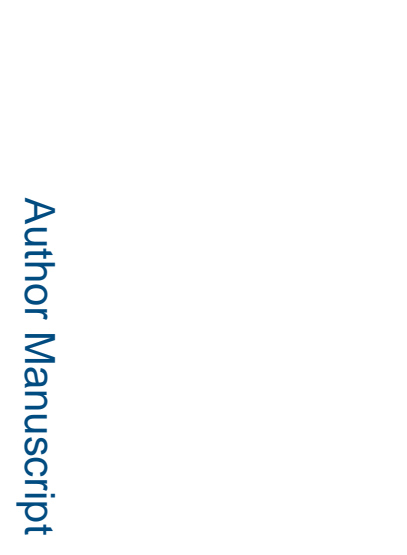

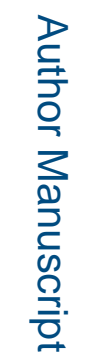
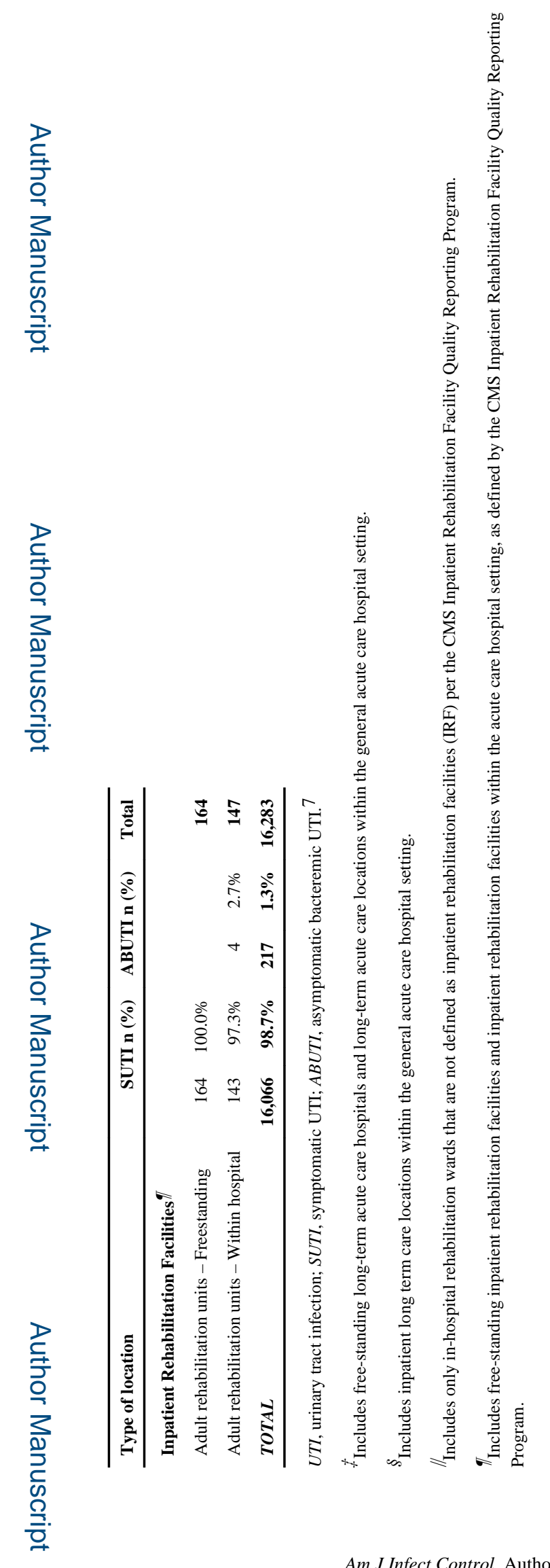

Am J Infect Control. Author manuscript; available in PMC 2015 October 29. 


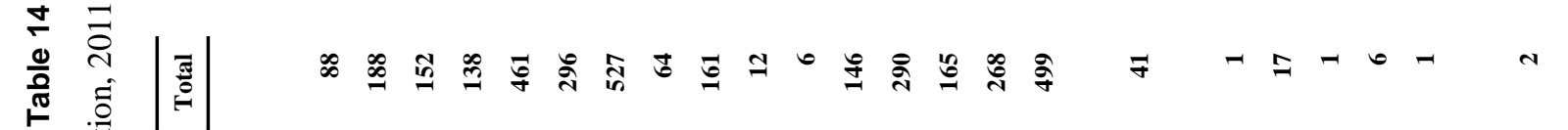

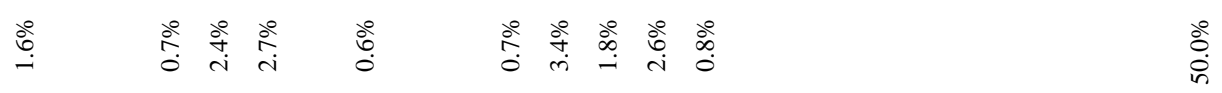
m

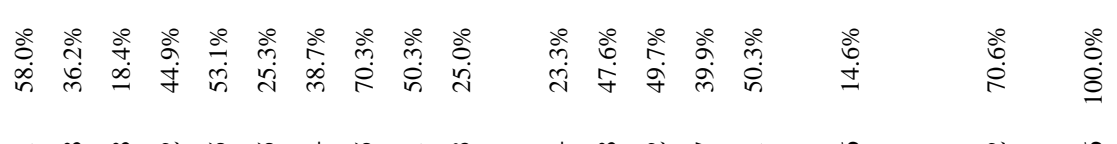

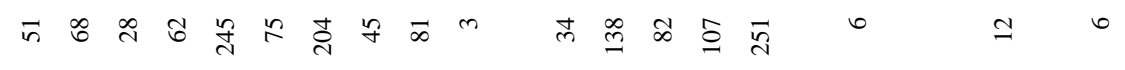

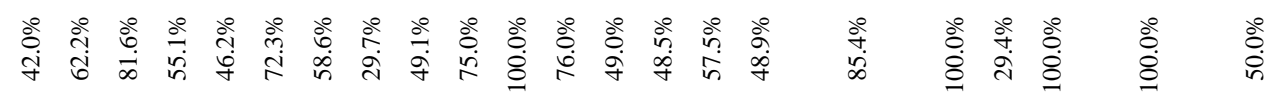

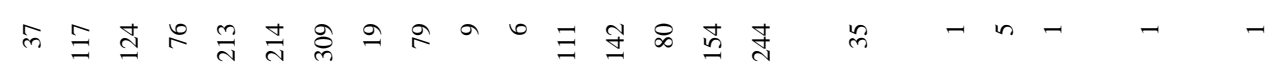

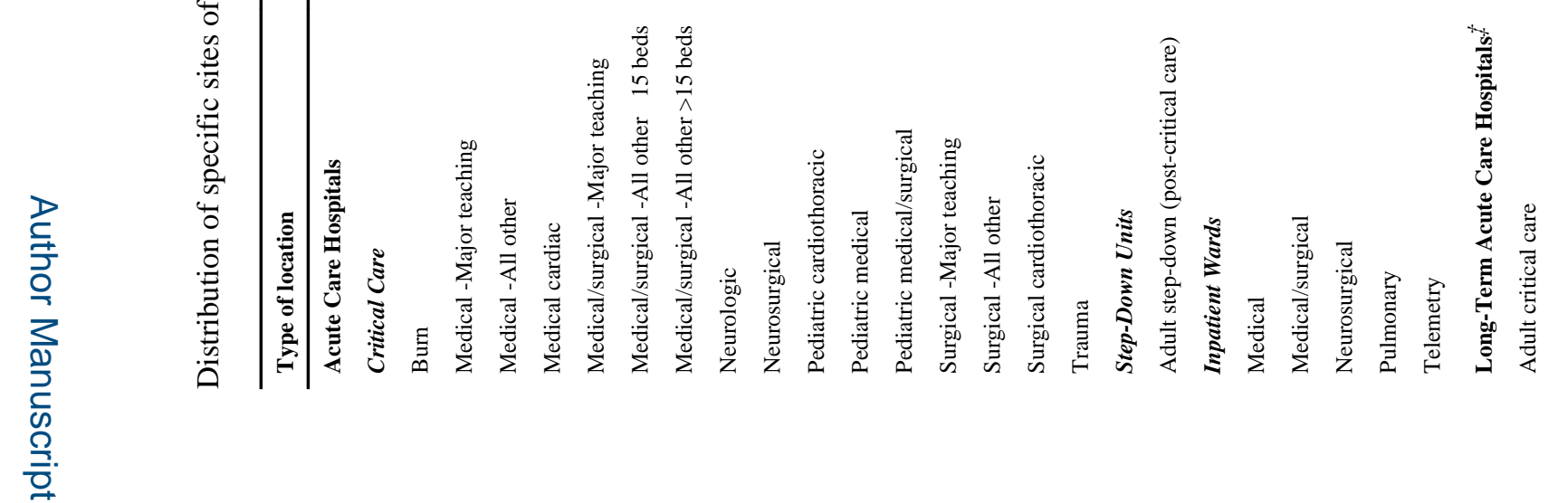
Am J Infect Control. Author manuscript; available in PMC 2015 October 29. 


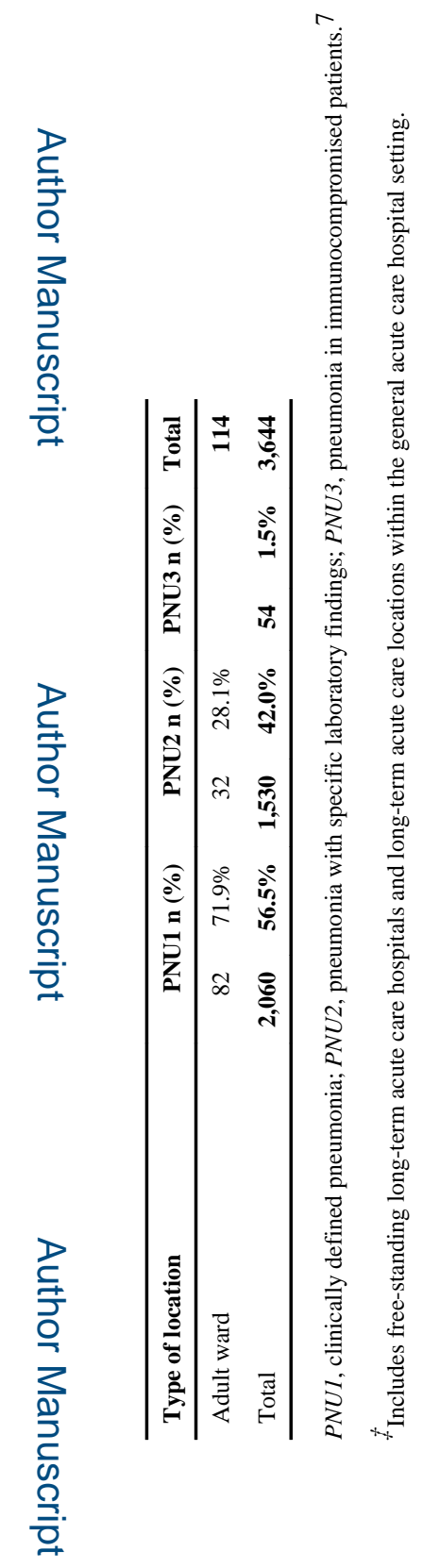

Am J Infect Control. Author manuscript; available in PMC 2015 October 29. 


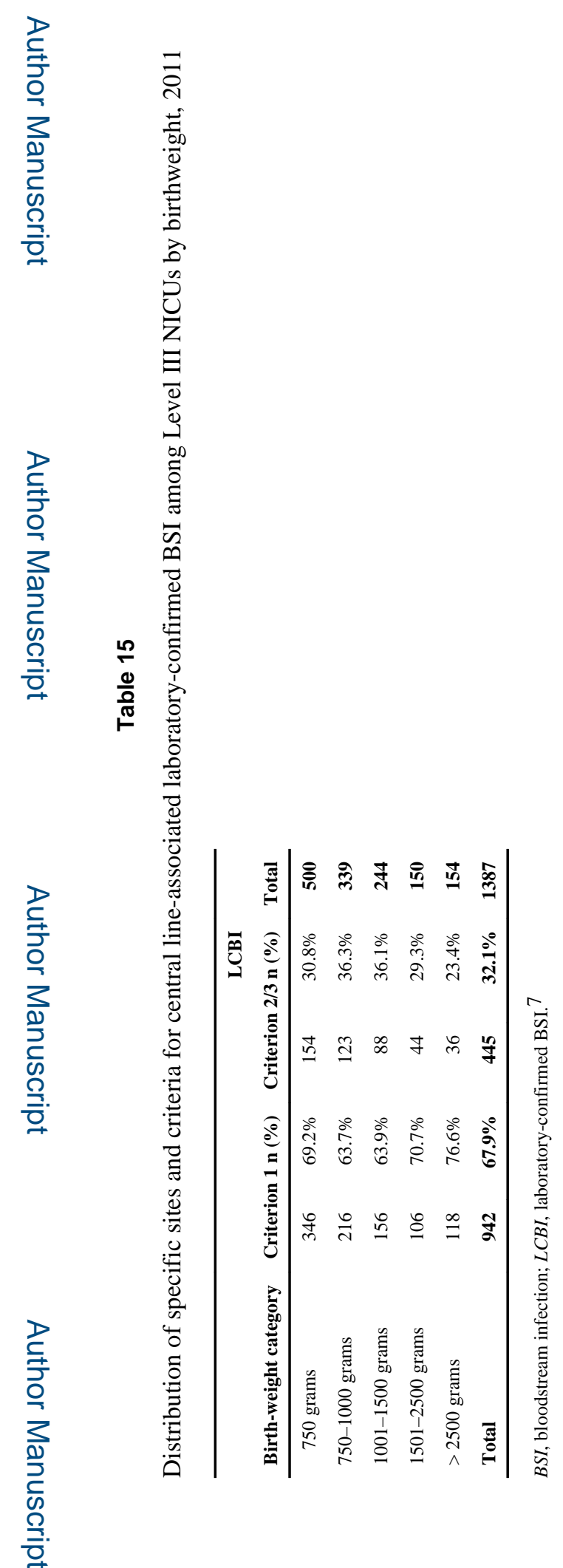

Am J Infect Control. Author manuscript; available in PMC 2015 October 29. 


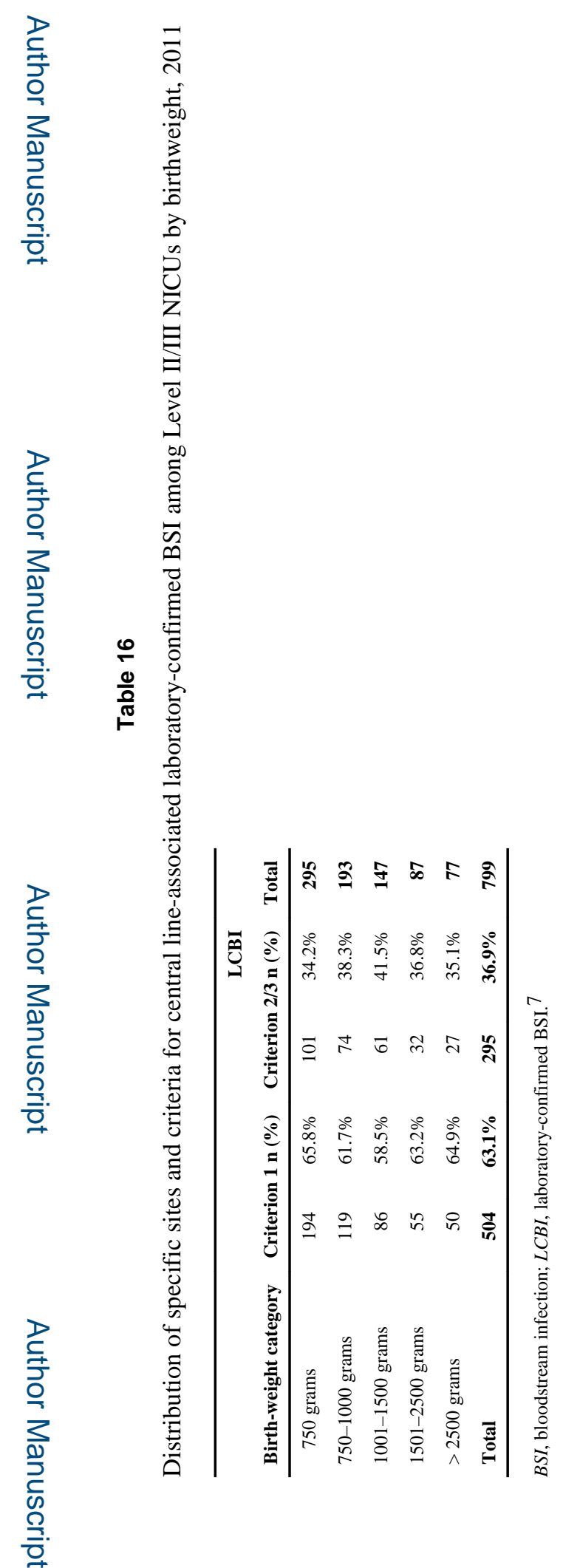

Am J Infect Control. Author manuscript; available in PMC 2015 October 29. 


\section{로을}

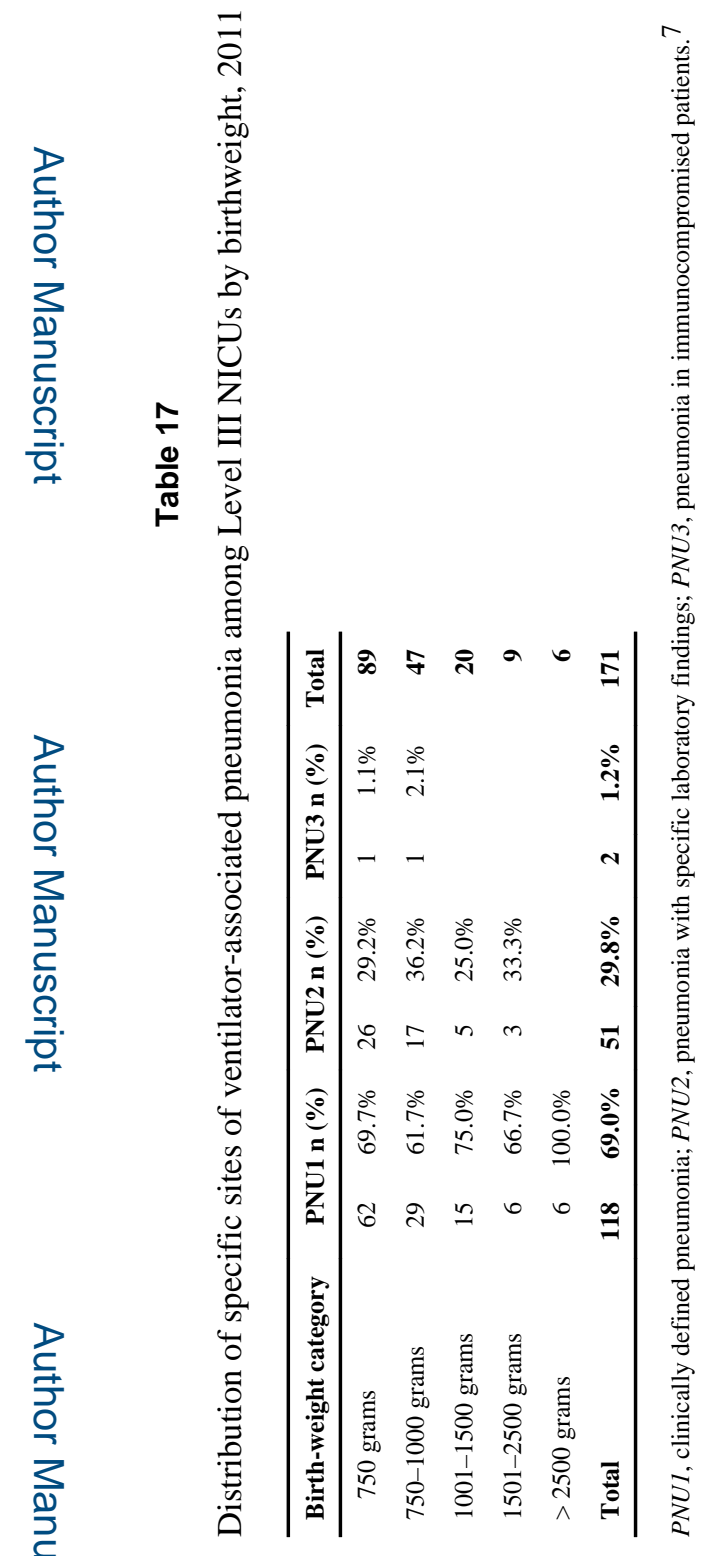

Am J Infect Control. Author manuscript; available in PMC 2015 October 29. 

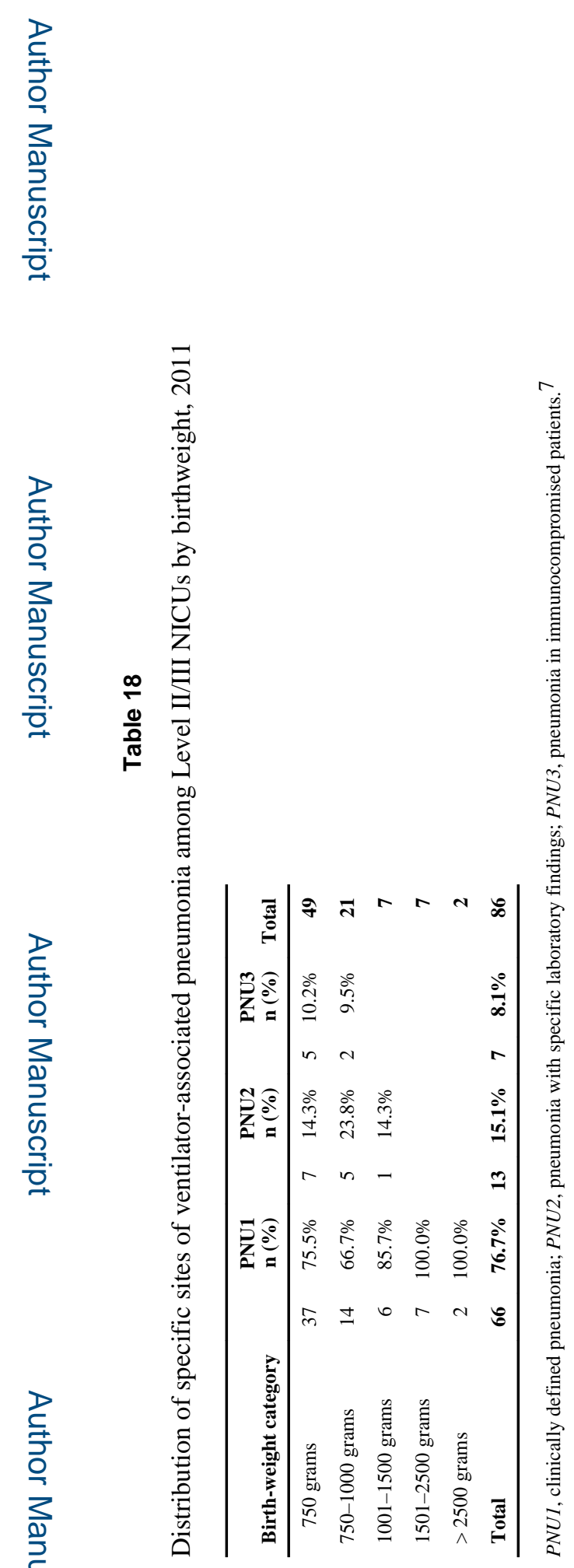